\title{
Giorgione e Tiziano al Fondaco dei Tedeschi $^{1}$
}

\author{
Alessandro Nova
}

L'architettura e la decorazione del Fondaco dei Tedeschi (fig. 1) sono da quasi tre secoli, senza tener conto delle fonti, al centro della ricerca degli eruditi e degli storici. Se mi permetto di invadere un terreno già perlustrato da tanti studiosi di vaglia, ciò avviene nella consapevolezza di non avere fra le mani un documento d'archivio inedito che possa aiutare a risolvere gli aspetti più controversi della sua storia, ma anche nella speranza che uno sguardo trasversale gettato da chi non si occupa a tempo pieno dell'arte di Giorgione e di Tiziano raggiunga, grazie anche al sostegno di un'immagine sinora ignorata, risultati nuovi puntando soprattutto su un'impostazione diversa dei problemi. Lo stimolo a occuparmi del Fondaco è giunto da due pubblicazioni recenti e di alto livello, da cui ho imparato molto pur non condividendone alcune premesse: $\mathrm{mi}$ riferisco a una delle ultime monografie dedicate alla figura di Giorgione, vale a dire al bel libro di Jaynie Anderson (1996), ${ }^{2}$ per molti versi encomiabile, e all'ottima scheda curata da Sandra Rossi nella versione italiana del catalogo della straordinaria mostra su Giorgione tenutasi prima a Venezia nel 2003 e poi a Vienna l'anno seguente. ${ }^{3}$ Ripeto, per evitare qualsiasi equivoco, di aver appreso molto da queste pubblicazioni e ne utilizzerò alcuni spunti. Tuttavia, il tentativo di identificare un programma iconografico con un tema specifico articolato su tutti gli spazi della facciata dipinta da Giorgione sul Canal Grande, che la Anderson crede di poter riconoscere nel mito di Ercole nel giardino delle Esperidi, mi sembra un problema mal posto né mi trovo d'accordo con chi sostiene la tesi di un programma iconografico unitario per le due facciate affrescate da Giorgione e da Tiziano su cui possediamo qualche informazione attendibile, poiché nulla sappiamo della decorazione delle pareti esterne del Fondaco rivolte verso nord, sul rio, e verso est, sulla salizzada. Per una serie di motivi che esporrò in seguito, le due facciate sul Canal Grande e sulle
Mercerie vennero realizzate per un pubblico non omogeneo e assolvevano pertanto a funzioni diverse, una considerazione che si ripercuote in modo implicito sui possibili temi iconografici illustrati dai due artisti. La mia tesi è in breve la seguente: compito dello storico non è solo quello di proporre una soluzione verosimile dell'enigma iconografico; altrettanto importante è definire che cosa s'intenda con il termine "programma" nel contesto delle facciate dipinte, perché il Vasari si trovasse a disagio di fronte al ciclo affrescato da Giorgione non riuscendo a decifrarne il tema e soprattutto stabilire se il carattere dell'opera fosse chiuso oppure aperto. Anticipo di non condividere l'opinione di chi si appella alle parole dello storico aretino, secondo cui gli affreschi di Giorgione vennero realizzati solo "per mostrar l'arte", poiché un palazzo dell'importanza strategica del Fondaco non avrebbe potuto essere decorato a piacere, ma di ritenere invece plausibile una forma "aperta" di programma iconografico molto diversa da quella a cui era abituato il Vasari.

Solo al termine dell'analisi delle fonti mi sono reso conto delle affinità fra la mia interpretazione e quella fornita da Ennio Concina nel suo volume sui fondaci veneziani. ${ }^{4}$ Ma poiché siamo giunti a risultati simili ponendoci in parte domande diverse e seguendo percorsi paralleli che solo in alcuni punti s'incrociano, mi sembra legittimo offrire la mia ricostruzione degli eventi a conferma dei risultati raggiunti ma anche a difesa di un metodo comune: sono infatti convinto che ci potremo avvicinare alla realtà storica della decorazione del Fondaco solo se lo affronteremo nella sua interezza, se non scomporremo il problema in unità minori e ne affronteremo invece la complessità. Di rado gli studiosi di Giorgione hanno dialogato con gli esperti del giovane Tiziano (ma qui ricordo almeno l'eccezione dei contributi di Giovanna Nepi Scirè e Francesco Valcanover sui frammenti del Fondaco presentati nel catalogo della mostra 


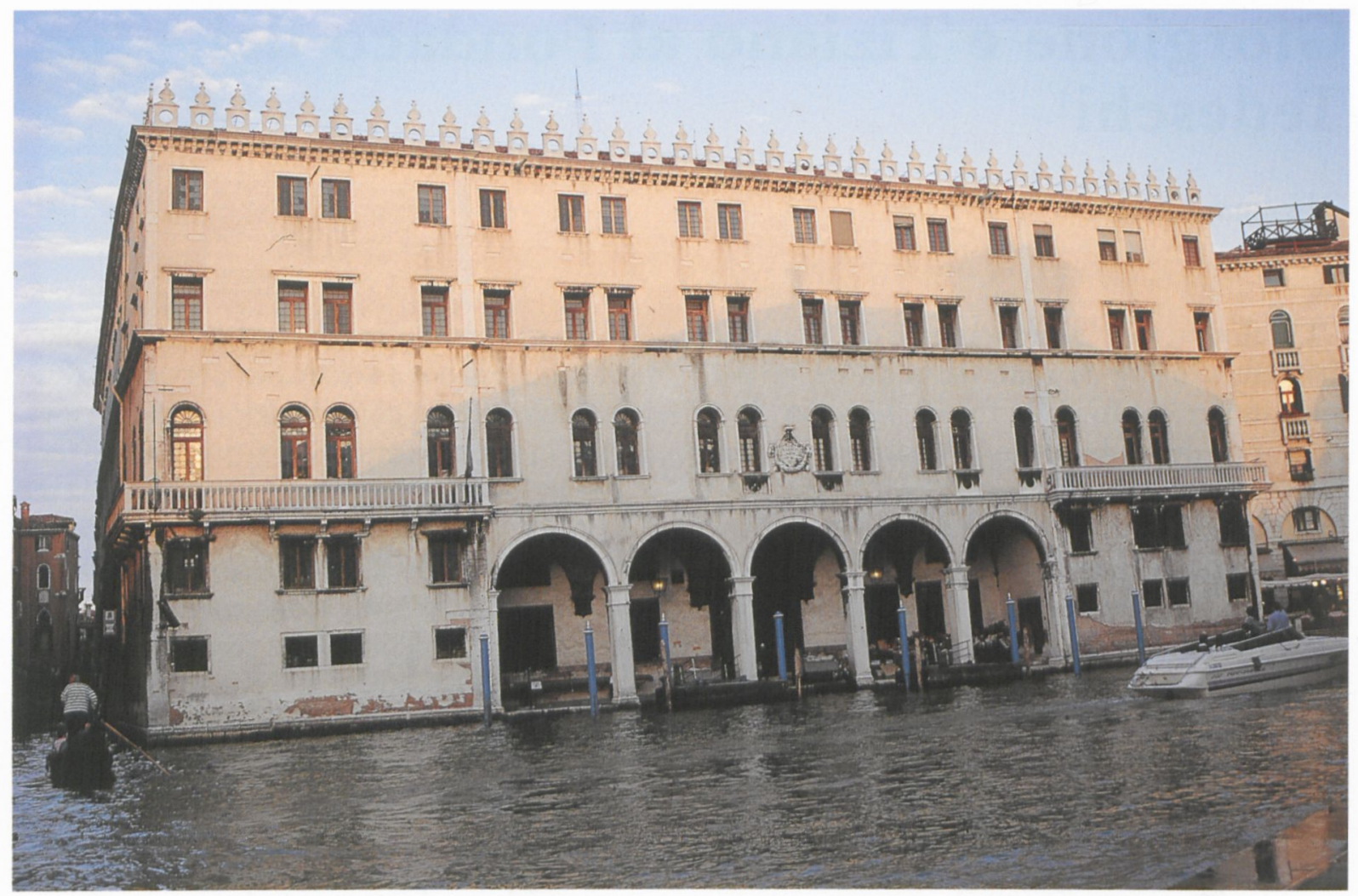

Fig. 1.Venezia, Fondaco dei Tedeschi, facciata sul Canal Grande (Foto Nova).

tenutasi alle Gallerie dell'Accademia nel $1978^{5}$ ) e troppo a lungo gli storici della pittura veneziana hanno separato i loro interessi dal manufatto architettonico. Penso invece che sia doveroso analizzare le pitture di Giorgione e di Tiziano nel loro contesto architettonico e sociale; il metodo pertanto, come detto, è identico a quello già impiegato da Concina, i risultati simili, ma le vie seguite alquanto diverse. Ed è per questo motivo che ritengo utile ripercorrere ancora una volta, benché in modo inevitabilmente selettivo, la storia del Fondaco privilegiando due aspetti, vale a dire il problema dell'autore del progetto, fermo restando che l'edificio realizzato fu il prodotto di un gruppo di tecnici pronti a soddisfare i precisi desideri dei committenti, e quello del pubblico, a cui è indissolubilmente collegato il tema del programma iconografico, senza ripetere $\mathrm{i}$ dati già raccolti, anche se a volte in modo frammentario, in contributi innumerevoli, ma formulando l'augurio che si giunga a una pubblicazione in cui tutte le immagini storicamente rilevanti e tutti i documenti d'archivio siano messi a disposizione degli studiosi, degli eruditi e dei curiosi.

\section{Il falso problema dell" "architetto" del Fondaco}

Le fonti d'archivio sulla storia del Fondaco erano già note ai padri della storiografia veneziana anche se la loro pubblicazione sistematica ebbe luogo nella seconda metà dell'Ottocento con l'edizione dei Diarii di Marin Sanudo e con i contributi degli storici tedeschi, da Georg Martin Thomas, compilatore nel 1874 del Capitular des Deutschen Hauses in Venedig, ${ }^{6}$ a Henry Simonsfeld, al quale spetta quella che a tutt'oggi è la storia più dettagliata dell'istituzione benché la sua monografia risalga al lontano $1887 .{ }^{7}$ I documenti relativi alle personalità coinvolte nella costruzione del Fondaco erano però stati messi sul tappeto già entro la metà del diciannovesimo secolo e le ipotesi allora formulate continuano a essere dibattute sino ai giorni nostri. Riassumendo i dati fondamentali, sono cinque le personalità artistiche legate in qualche modo alla storia architettonica del Fondaco: quella di Pietro Lombardo, evocata da Tomaso Temanza nelle sue Vite dei più celebri architetti e scultori veneziani del sedicesimo secolo, è stata giustamente da 
tempo accantonata poiché priva di qualsiasi riscontro documentario o stilistico. ${ }^{8}$ Restano quindi i nomi elencati dalle fonti: Hieronymus Tedesco, Giorgio Spavento e lo Scarpagnino a cui si è aggiunto su basi documentarie non molto solide quello di Fra Giocondo. Giovanni Antonio Selva fu il primo a ricordare senza giudizi qualificanti, anzi sostenendo l'anonimità dell'autore del Fondaco, come il frate domenicano fosse identificato quale architetto della struttura in un poema elegiaco composto da Pietro Contarini di Giovanni Alberto risalente al 1517 e conservato nella Biblioteca Marciana sotto il titolo In m. Andream Grittum panegyris. ${ }^{9}$

Il Thomas invece attribuì il Fondaco direttamente a Fra Giocondo e da allora, benché venisse smentito subito con buoni argomenti dal Simonsfeld, ${ }^{10}$ una linea storiografica ha privilegiato questa soluzione: da Manlio Dazzi, che seguì da vicino i restauri radicali del Fondaco terminati nel $1939,{ }^{11}$ alla sintesi grandiosa di Manfredo Tafuri sul Rinascimento a Venezia, ${ }^{12}$ anche se il primo sembra tentennare alla fine della sua analisi mentre il secondo riduce il ruolo del frate a quello di consulente, soprattutto per la soluzione del cortile interno ad arcate sovrapposte che troverebbe un riscontro in un'illustrazione del Vitruvio pubblicato dall'artista veronese nel 1511.

In realtà, a prescindere dalla data del ritorno a Venezia di Fra Giocondo dalla Francia, sappiamo che egli iniziò a lavorare ufficialmente per la Signoria il 28 maggio 1506, solo due mesi prima della messa in opera del primo solaio del Fondaco, quando evidentemente le fondamenta dell'opera erano già state gettate da tempo, e che nel 1507 l'architetto si lamentava con il Collegio per la sua inattività. ${ }^{13}$ Può darsi quindi che Fra Giocondo abbia fornito il suo parere sulla costruzione del Fondaco, ma l'impressione è che il suo apporto sia stato di recente sopravvalutato. Le fonti in nostro possesso sono limpide e chi vuole ampliare il ruolo del frate deve fare i conti con una documentazione che lascia pochi spazi di manovra. In ogni caso si deve partire da una premessa di metodo: se i documenti contabili a noi noti ci tramandano senza incertezze i nomi di Hieronymus Tedesco, di Giorgio Spavento e dello Scarpagnino, su quali basi possiamo spendere il nome di Fra Giocondo? La risposta non può che essere: su inoppugnabili dati di fatto o di stile. Tuttavia, da un punto di vista documentario è evidente che le delibere dell'amministrazione veneziana e la contabilità della fabbrica sono da preferire alle allusioni del panegirico di Pietro Contarini, ${ }^{14}$ una fonte poco attendibile secondo Concina. ${ }^{15}$ Mentre gli elementi stilistici su cui insistono alcuni possono essere sì confrontati con un linguaggio genericamente all'antica, ma non sono tali da giustificare un coinvolgimento diretto alla progettazione del Fondaco da parte del frate domenicano.

Pertanto, al di là di una possibile ma vaga consulenza di Fra Giocondo, possono restare in gioco solo tre nomi, quelli ricordati dalle fonti amministrative. Senonché gli studi non sembrano trovare pace nemmeno su questo fronte: se Pietro Selvatico nella sua storia dell'architettura e scultura veneziana del $1847^{16}$ e Francesco Zanotto nelle note alla terza edizione, apparsa nel 1858, de Le fabbriche e i monumenti cospicui di Venezia dell'équipe coordinata dal Cicognara ${ }^{17}$ ritenevano che lo Hieronymus Tedesco ricordato dai documenti e dal Sanudo fosse l'architetto del Fondaco, molti storici più vicini al nostro tempo hanno sottolineato invece i caratteri veneziani della costruzione privilegiando il nome dello Spavento, poiché al giovane Scarpagnino, chiamato a dirigere i lavori di edificazione del Fondaco a partire dal 13 ottobre 1505 , non può essere riconosciuto un ruolo creativo nella progettazione della struttura. ${ }^{18}$ Lo Scarpagnino diventerà sì il tecnico principe dell'architettura veneziana dei decenni a venire, l'alternativa locale al Sansovino, ma negli anni del Fondaco era ancora uno strumento nelle mani del potente proto di San Marco, quel Giorgio Spavento che scomparve il 17 aprile 1509, come c'informa il Sanudo, poco dopo il completamento del Fondaco dei Tedeschi. ${ }^{19} \mathrm{La}$ documentazione in nostro possesso non lascia adito a dubbi. La costruzione dell'edificio venne assegnata allo Spavento - e vedremo fra poco il perché - ma questi, impedito dai molti impegni legati alla sua funzione di proto di San Marco, lasciò allo Scarpagnino l'incarico di realizzare materialmente il Fondaco, mentre quest'ultimo, da poco giunto a Venezia, non era ancora ben inserito nell'ambiente della città per poter ambire a una totale autonomia nella direzione di un cantiere così prestigioso. Ciò significa che la que- 
stione è risolta e che lo Spavento deve essere considerato come il vero architetto del Fondaco dei Tedeschi? Per nulla e in un saggio recente Giandomenico Romanelli lamentava lacune e incertezze, concludendo in questo modo: "Allorché si parla del Fondaco dei Tedeschi [...] ci si pone il problema - mai definitivamente risolto - del suo misterioso architetto. E il ventaglio dei nomi da sempre agitato attorno ai pochi ma non equivoci documenti pervenutici sta anche a denunciare la natura assai complessa della questione, proprio a partire dalla scelta di un architetto tedesco, tale Hieronymus, che sembra un'accorta concessione di rappresentanza alla comunità dei mercanti teutonici più che la convinta e convincente adozione di un partito architettonico." 20 Tutto vero e condivisibile. Eppure la documentazione in nostro possesso non è poi così ambigua da impedirci di ricostruire uno scenario credibile. Ancora una volta si deve insistere su premesse di metodo. Che cosa ci dicono i documenti? E se non vogliamo credere a quel che ci raccontano possiamo smentirli appellandoci allo stile o ad altre prove indiziarie? Altro non possiamo né dobbiamo fare. Partiamo quindi ancora una volta dalle fonti. ${ }^{21}$

In seguito all'incendio divampato nella notte fra il 27 e il 28 gennaio 1505 , che nei due giorni seguenti distrusse completamente il Fondaco dei Tedeschi, il Collegio, riunitosi il 6 Febbraio, decise una ricostruzione rapida e opulenta di una struttura commerciale di grande interesse strategico. Alla seduta di febbraio era presente d'ufficio anche il proto di San Marco, vale a dire Giorgio Spavento, e il 15 marzo la Signoria era già impegnata a discutere il progetto del nuovo Fondaco. In primavera tuttavia devono avere avuto luogo dei colloqui con la Nazione tedesca perché contrariamente ai costumi della Repubblica venne indetto, a quanto pare, un concorso a cui parteciparono almeno Giorgio Spavento e un non meglio identificato Hieronymus tedesco. ${ }^{22}$ La presentazione al Collegio di diversi modelli, almeno tre, è testimoniata in un decreto dei Pregadi emanato il 19 giugno 1505; questo documento è noto almeno sin dai tempi dell'abate Cadorin, i cui Pareri vennero citati dal Zanotto nella nota (1858) a Le fabbriche di Venezia del Cicognara, ma poiché è il testo chiave nella storia della ricostruzione del Fondaco è bene riportarlo per intero nella trascrizione dell'o- riginale fornitami dalla cortesia di Charles Hope, anche perché in molti saggi esso viene spesso citato in modo frammentario e a volte involontariamente tendenzioso (il corsivo è aggiunto per mettere in risalto alcune frasi):

"Havendosi cum diligentia visti et ben examinati $i$ modeli del fontego di Thodeschi apresentadi a la Signoria nostra et considerà non esser gran differentia de spesa da l'uno et l'altro, l'è ben conveniente satisfar a la grande instantia facta per li mercadanti de esso fontego, $i$ quali, dovendo esser quelli che lo hanno a galder et fruir, hanno supplicato se vogli tuor el modello fabricado per uno del suo nominato Hieronymo, homo intelligente et practico, per esser non mancho de ornamento de questa cità et utele de la Signoria nostra che comodo ad loro, si per la nobel et ingeniosa composizione et constructione de quello come etiam per la quantità e qualità de le camere, magazeni, volte et botege se farano in esso, de le quali tute se trazerà ogni anno de afficto bona summa de danari; perho [perciò?] [...] per auctorità de questo conseglio la fabriga del fontego suprascripto far se debi iuxta el modello composto per el prefato Hieronymo Thodescho, et accadendo quello conzar over modificar in parte alcuna ad benefitio de la Signoria nostra et commodo de le mercadantie haverano ad star in esso, sia dà libertà al Collegio nostro, a bossoli et ballote, passando i do terzi, posserlo fare si come li parerà expediente, cum questo perho, che la faza et rive da la banda davanti non sia in parte alcuna alterada né mossa, immo sia facta et reducta secondo la forma de esso modello, tutta volta che'l non se possi ussir più fuori in Canal Grando cum li scalini de le rive de quello è al presente la fondamenta, et ulterius dove da basso sono magazeni da la parte de fuori redur si debi in tante botege et volte come stano $i$ altri modelli, né se possi in esso fontego far cossa alcuna de marmoro, né etiam lavoriero alcuno intagliado de straforo, over altro per alcuno modo, ma dove l'acaderà far se debi de piera viva batuda de grosso et da ben, sì come serà bisogno.

De parte 166 [voti]

De non 19
Non sincere [astenuti] $0 .{ }^{23}$

Da questa fonte ricaviamo alcune informazioni preziose. Prima di tutto i modelli presentati furono almeno tre poiché verso la fine del documento si accenna a migliorie da apportare al progetto di Hieronymus sulla scorta degli 
altri modelli. Può darsi che lo Spavento ne abbia apprestati due, come qualcuno ha suggerito, ma è più probabile che $\mathrm{i}$ contendenti fossero almeno tre poiché non mi è noto un altro caso in cui un artista del primo Cinquecento abbia partecipato a un concorso architettonico presentando più di un modello. In ogni caso il tedesco risultò vincitore, come c'informa anche il Sanudo: "A dì 19 [giugno 1505] [...] Fu posto, per il colegio, il modello dil Todesco, e secondo quello si fazi il fontego di todeschi, e si fazi le botege a torno, e il colegio habi libertà, per le do parte, a bosoli et balte, terminar quello li parerà." 24 È importante che l'attribuzione a Hieronymus Tedesco del modello del Fondaco approvato dal Collegio provenga da due fonti indipendenti poiché ciò garantisce la veridicità della notizia. E vero tuttavia che i committenti lasciarono aperto un varco a possibili modifiche. Come dire: per venire incontro alle richieste degli ospiti d'Oltralpe approviamo il progetto del loro concittadino, pur riservandoci il diritto di poter intervenire in corso d'opera e quindi di modificarne la struttura. Questa clausola ha consentito a molti storici dell'arte di rimuovere completamente dalla scena Hieronymus Tedesco, ${ }^{25}$ ma un'altra clausola dello stesso decreto prevedeva che la facciata sul Canal Grande non avrebbe dovuto essere alterata per nessuna ragione. Parole forti. Qual era il motivo di una decisione così perentoria? Perché non era lecito modificare il prospetto disegnato da Hieronymus? Dobbiamo dedurne che la facciata odierna, pur con tutti i rimaneggiamenti subiti da un oggetto protagonista di molti secoli di storia, deve essere fatta risalire almeno in parte al suo progetto? Per il momento non vedo altre alternative poiché chi desidera smentire la decisione registrata nel decreto conservato nelle carte dei Pregadi deve riuscire a soddisfare almeno una di queste tre condizioni: 1) rintracciare dei documenti in cui si dimostri che il Collegio o chi per lui abbia deciso di modificare il modello dell'architetto tedesco; 2) provare che Hieronymus non sarebbe mai stato in grado di progettare la facciata che vediamo oggi; 3 ) oppure dimostrare che il Fondaco parla inconfondibilmente la lingua di un architetto locale, come lo Spavento o lo Scarpagnino. Tuttavia, nessuna di queste tre strade è percorribile senza riserve o compromessi. Per quanto concerne il primo punto già il Dazzi aveva notato che non esistono delibere di modifica, anche se questo argomento ex silentio non può essere accolto come una prova inconfutabile dell'inesistenza di tali modifiche. Se le varianti al progetto non sono documentate dalle carte d'archivio tramandateci, ciò non vuol dire che esse non siano state in effetti apportate. Opinione condivisibile, ma se seguiamo un metodo storico non possiamo far altro che partire dai dati certi e questi ci dicono che il progetto di Hieronymus venne approvato dal Collegio mentre la sua eventuale modifica non è registrata in alcuna fonte. Ciò significa che solo un'argomentazione stilistica può soccorrerci, se vogliamo negare a Hieronymus la paternità del progetto.

Per quanto concerne il secondo punto ci troviamo però di fronte a un paradosso: non siamo in grado di decidere se il Fondaco sarebbe rientrato nelle possibilità progettuali di Hieronymus per il semplice fatto che di lui non sappiamo assolutamente nulla. In passato non è mancato chi cercasse di ricostruirne una presunta attività ad Augusta e dintorni, ma, come Puppi ci ha ricordato, "'Hieronimus' architetto è figura pressoché ignota alla storia dell'arte." 26 Ribaltando il pensiero del Dazzi, secondo cui l'assenza di carte d'archivio che documentino una modifica del piano originale non implica l'impossibilità di tali modifiche, si potrebbe tuttavia controbattere che l'assenza di altre opere indiscutibilmente attribuite a Hieronymus non può essere utilizzata come argomento per sostenere l'inesistenza anagrafica di un architetto di nome Hieronymus.

Resta pertanto solo la possibilità di dimostrare che il Fondaco rientri senza ombra di dubbio nel linguaggio stilistico dello Spavento e dei suoi aiuti, ma se sfogliamo il repertorio dell'architettura veneziana del McAndrew è difficile imbattersi in elementi paragonabili a quelli impiegati nella realizzazione del Fondaco dei Tedeschi, anche perché l'edificio imponente e multifunzionale costituisce un unicum nel panorama architettonico di Venezia. ${ }^{27}$

In realtà, a me sembra che l'interrogarsi sull'identità dell'architetto del Fondaco sia un falso problema o quanto meno una questione impostata male. La mescolanza di elementi veneziani, nordici e persino mediterranei della struttura è infatti lo specchio eloquente di un'opera pianificata in modo pragmatico, cresciuta attraverso discussioni collegiali e realizzata giorno per giorno affrontando i problemi 
del momento. E se leggiamo senza pregiudizi la letteratura specifica, al di là dei proclami interessati a favore di questa o quella personalità artistica, vedremo che le diverse opinioni tendono a convergere verso questa soluzione. Persino il Dazzi, uno dei fautori più ostinati dell'autografia di Fra Giocondo, terminava il suo saggio identificando l'architetto del Fondaco nei committenti e valutando la struttura come un'opera di collaborazione fra - cito — "l'ordinata distribuzione tedesca [... e le] chiare forme architettoniche del rinascimento italiano." 28 Anche il Tafuri, pur affascinato dal possibile ruolo svolto dal frate domenicano, sembrava privilegiare alla fine della sua analisi una forma di collaborazione fra il mestiere di Giorgio Spavento e le aspirazioni magniloquenti di Fra Giocondo. ${ }^{29}$ Ma fra le diverse proposte con cui si è cercato di fare chiarezza sull'argomento trovo più congeniale quella avanzata dal Concina che pur non negando gli accenti classicheggianti della struttura, vale a dire il famoso cortile ad arcate sovrapposte, non trascura i riferimenti mediterranei e i rapporti con il nord. La sobrietà e l'austerità della struttura sembrano infatti parlare un linguaggio europeo, molto diverso dal ricco decorativismo tardogotico delle facciate precodussiane sul Canal Grande. E se sarebbe sbrigativo attribuire su queste basi il progetto a Hieronymus sarebbe altrettanto arbitrario negargli qualsiasi ruolo. Citando e parafrasando le parole di Concina, "una parte degli aspetti funzionali e distributivi dell'edificio gli deve essere riconosciuta" e a Hieronymus va fatta risalire la facciata d'acqua dove si riscontrano caratteristiche non veneziane poiché "il porticato terreno di approdo contrasta [con] l'assenza delle polifore ai piani superiori." Si verifica pertanto l'abbandono di un elemento chiave e qualificante della cultura architettonica veneta. Allo stesso maestro andrebbe inoltre attribuita la rinuncia al modello veneziano di sala di rappresentanza con una polifora di affaccio e la sua sostituzione con le due sale d'angolo del piano nobile, affini piuttosto ai refettori e alle sale da riunione delle sedi nordeuropee delle corporazioni mercantili tedesche. ${ }^{30}$

Condivido questa analisi: l'aspetto collettivo dell'operazione, su cui s'innestano i successivi interventi dello Spavento e dello Scarpagnino, fa ritenere che il progetto originale del maestro tedesco debba essere sopravvissuto in qual- che sua parte nell'edificio tuttora in opera. Ma se a Hieronymus spetta verosimilmente la prima idea del Fondaco così come esso ci è giunto e come dobbiamo per forza continuare a credere fino a quando non rintracceremo delle chiare smentite documentarie, quali elementi caratterizzanti ne articolavano il progetto? Perché il decreto stabiliva che non si dovesse alterare in alcun modo la facciata da lui progettata sul Canal Grande?

Le spiegazioni e le proposte di Concina sono, dal punto di vista del linguaggio architettonico, convincenti, anche se non si deve dimenticare che la soluzione delle due sale d'angolo era determinata sia da ragioni climatiche (refettorio d'inverno nel cantone a sud-ovest e refettorio d'estate in quello rivolto verso nord-est) e sia dai particolarismi nazionali poiché i mercanti tedeschi cenavano separati dai membri appartenenti alle altre nazioni nordeuropee. Ma un passo del decreto dei Pregadi suggerisce, in aggiunta alle considerazioni già espresse dal Concina, che il progetto di Hieronymus prevedesse sin dall'inizio dei lavori una facciata dipinta sul Canal Grande. Si potrebbe negare questa ipotesi sostenendo che, se ciò fosse vero, il documento avrebbe probabilmente registrato questo aspetto del modello in modo esplicito, ma una frase del testo permette di spingerci in questa direzione. Il passo chiave è quello in cui si ricorda come i mercanti tedeschi abbiano presentato una supplica al governo veneziano affinché venga favorito il modello presentato da un loro connazionale chiamato Hieronymus e poiché la soluzione escogitata dal maestro d'oltralpe, a parità di spesa, risulterà di beneficio e ornamento tanto alla città quanto agli uomini d'affari della Nazione tedesca, ci si augura che essa venga realizzata in quel modo "sì per la nobel et ingeniosa composizione et constructione.” Perché si opera nel documento una distinzione fra "composizione" e "costruzione"? Per quale motivo la composizione deve essere particolarmente ingegnosa, vale a dire inusuale nel panorama cittadino?

Quando oggi ci sediamo di fronte alla spoglia facciata del Fondaco non possiamo fare a meno di rimpiangere la perdita quasi totale degli affreschi di Giorgione, non solo per la loro intrinseca qualità di opera d'arte tanto lodata dalle fonti ma anche perché essi erano parte integrante dell'invenzione architettonica. Senza quegli affreschi la facciata resta muta, quasi sen- 
za valore e il solo merito dell'attuale situazione è quello di rivelarne la semplicità disarmante. Non ci voleva un architetto di genio per progettare questo prospetto e non si capisce perché debba essere negato alla personalità che le fonti ci indicano con evidente chiarezza. Il compito era sì tecnicamente molto impegnativo e fu questo uno dei motivi per cui lo Spavento e lo Scarpagnino vennero incaricati della realizzazione materiale del progetto, ma la distribuzione dei volumi all'interno della fabbrica e la conseguente disposizione delle aperture nelle pareti erano così monotone da giustificare l'ipotesi che questo edificio disadorno e funzionale fosse stato progettato sin dall'inizio con facciate dipinte, in modo che la costruzione fosse alleggerita da una "composizione nobile e ingegnosa", per ripetere le parole del decreto.

Lo stesso documento c'informa inoltre che la struttura del Fondaco non avrebbe dovuto essere impreziosita da decorazioni marmoree né da lavori d'intaglio o a straforo, non solo per contenere i costi ma anche per realizzare velocemente l'opera. È pertanto possibile che i committenti abbiano assegnato ai partecipanti al concorso una direttiva in questo senso e che tutti i progetti venissero realizzati tenendo in considerazione necessità di risparmio ed efficienza. Ma non si può resistere alla tentazione di collegare la soluzione della facciata dipinta con figure monumentali ai desideri della nazione tedesca e pertanto alla figura del suo "architetto" di fiducia. È infatti possibile se non probabile che i mercanti abbiano colto l'occasione propizia per imporre a Venezia una tipologia decorativa che proprio in quel momento si stava diffondendo rapidamente in tutti i territori dell'impero. Con questo non intendo sostenere che la tipologia delle facciate dipinte fosse sconosciuta in laguna. $\mathrm{Al}$ contrario, il tema è stato al centro di numerose pubblicazioni sin dai tempi degli studi pionieristici di Lodovico Foscari ${ }^{31}$ per poi esplodere negli anni '70 e ' 80 in sintonia con lo sviluppo di una responsabile politica ambientale nel campo dei beni culturali. Mi rammarico di non aver potuto consultare le minuziose indagini sugli intonaci dipinti a Venezia compiute da un'équipe coordinata dall'architetto Mario Piana (mai pubblicate, per quanto ne sappia ${ }^{32}$ ) e del resto basta rivolgersi ai dipinti di Gentile Bellini, Carpaccio e Mansueti per rendersi conto del- l'ampiezza del fenomeno. Tuttavia, sono proprio quelle immagini, oltre ad altre fonti scritte, a confermare che prima del Fondaco mai nulla di simile, per complessità e proporzioni, era stato tentato a Venezia. ${ }^{33} \mathrm{Nel}$ tredicesimo e quattordicesimo secolo i muri erano decorati perlopiù con affreschi decorativi a motivi geometrici o vegetali. E anche quando le facciate con elementi figurativi acquistarono un peso maggiore nel corso del Quattrocento, esse non raggiunsero mai l'articolazione ambiziosa del ciclo affrescato da Giorgione. Sappiamo che proprio nella zona di Rialto alcuni edifici pubblici erano stati decorati con affreschi esterni nel tardomedioevo, ma non è del tutto certo che il Palazzo del Comune ricordato da Francesco Sansovino nella Venetia città nobilissima fosse veramente decorato con pitture murali all'esterno ${ }^{34}$ e proporrei di distinguere fra affreschi genericamente all'aperto, ad esempio al riparo di logge coperte, assai diffusi e la più rara tipologia delle facciate dipinte con temi profani. ${ }^{35}$

Se delimitiamo il campo in questo modo, le fonti sono piuttosto avare. L'esempio meglio conservato risulta infatti l'edificio a lato del ponte di San Lorenzo rappresentato nel Miracolo delle reliquia della vera croce dipinto da Gentile Bellini per la Scuola di San Giovanni Evangelista nell'anno 1500 e ora all'Accademia, dove il piano nobile è decorato con figure monumentali di fauni e canefore, mentre quello superiore è affrescato con una serie di trofei militari all'antica che dovevano essere molto diffusi sulle facciate veneziane. L'altra fonte inoppugnabile, oltre alle suggestive fantasie illustrate da Jacopo Bellini nei suoi due libri di schizzi, è la pianta di Venezia di Jacopo de' Barbari, anch'essa risalente al 1500, dove tuttavia appare una sola facciata dipinta con motivi figurativi, quella del palazzo Giustinian-Persico sempre nel sestiere di San Polo. È possibile che essa funga per così dire da figura retorica, che essa sia indicata dal de' Barbari come pars pro toto di un fenomeno più ampio, ma trovo convincente la tesi di Bruno Nogara secondo cui l'artista sarebbe stato spinto a riprodurre questa facciata istoriata perché incuriosito dalla novità dell'abbandono dei motivi gotici tradizionali. ${ }^{36}$ In ogni caso, in tutta la letteratura specializzata sull'argomento ritornano sempre le stesse considerazioni e conclusioni: pur ammettendo che il fenomeno 
dovette essere più esteso di quanto oggi non sia documentabile, si fa risalire alla seconda metà del Quattrocento il salto di qualità nelle decorazioni delle facciate veneziane. Gli esempi documentati da Gentile Bellini e Jacopo de' Barbari indicano tuttavia quanto limitata fosse la gamma dei motivi iconografici. Ben più articolato era invece il repertorio sviluppatosi nelle città della terraferma e questo deve essere, per inciso, il motivo per cui la decorazione del Fondaco venne affidata a un pittore della marca trevigiana non ancora del tutto affermato a livello pubblico e a una giovane promessa del Cadore. ${ }^{37}$ È possibile che i migliori pittori veneziani non volessero sporcarsi le mani con un incarico non remunerato a sufficienza, ma se persino la decorazione del palazzo più imponente al centro della città commerciale non era per loro allettante, ne possiamo dedurre che $\mathrm{i}$ grandi maestri della Serenissima si tennero alla larga da questa tipologia che richiedeva una particolare esperienza. Un'arte invece assolutamente padroneggiata dai pittori di terraferma. È curioso, ma la seguente domanda sembra essere stata trascurata: come hanno potuto assicurarsi due giovani artisti provenienti dalla provincia della Repubblica un'allogazione tanto prestigiosa? La risposta, lo ripeto, va forse cercata nella ricompensa abbastanza modesta per i disagi patiti su ponteggi eretti all'aperto, ma forse è più vicino al vero chi ipotizza che i due avessero alle spalle non solo i giusti contatti ma anche esperienze di lavoro all'altezza dell'occasione. ${ }^{38}$

Qualunque sia la verità storica, ma il quadro tracciato sinora vi si deve avvicinare di molto, quasi tutti gli studiosi sono in ogni caso concordi nel ritenere che la facciata affrescata da Giorgione, pur radicata in una tradizione locale, abbia costituito un salto di qualità nella storia di questa tipologia in città e resta comunque il fatto che le facciate dipinte a soggetto profano nella Venezia del quindicesimo secolo sono mal documentate, che $\mathrm{i}$ dati visivi in nostro possesso (Bellini, Jacopo de' Barbari) indicano un repertorio alquanto limitato e che il programma del Fondaco abbia segnato, fino a prova contraria, una svolta a Venezia di cui dobbiamo sondare le cause. ${ }^{39}$

La moda delle facciate dipinte a motivi figurativi godeva invece di grande popolarità nei paesi d'Oltralpe almeno dal quattordicesimo secolo e fu esattamente nel periodo delle tensioni e delle contese con l'imperatore Massimiliano che sorsero numerose iniziative analoghe a quella del Fondaco, da Vienna a Innsbruck, da Ratisbona a Norimberga, da Augusta a Trento. Mi sembra pertanto plausibile proporre che il progetto presentato da Hieronymus tedesco al Collegio prevedesse sin dall'origine un prospetto dipinto in modo elaborato sul Canal Grande perché solo così possiamo spiegare la semplicità della facciata. Una soluzione che avrebbe potuto rafforzare il senso d'identità dei mercanti tedeschi residenti all'estero e che non giungeva sgradita al governo veneziano sia per la sua praticità e sia per la sua sostanziale novità benché restasse ancorata a esperienze culturali già collaudate in laguna.

È tuttavia evidente che una tale proposta può essere accolta solo a ben precise condizioni e con la prudenza di rito: se il progetto di Hieronymus non venne solo accolto ma anche realizzato, l'esecuzione materiale dell'edificio con le possibili varianti restò saldamente nelle mani degli architetti veneziani. Per due motivi: perché gli stranieri non potevano esercitare liberamente la loro professione a Venezia se non a scapito di pesanti intimidazioni (si pensi alle parole avvelenate di Dürer che si lamentava a ragione dell'invidia e del comportamento aggressivo dei colleghi veneziani), ma soprattutto perché un capomastro d'Oltralpe non avrebbe mai avuto la competenza, quello che oggi definiremmo know-how, per erigere una mole gigantesca sull'acqua. Le carte d'archivio che documentano l'attività dello Spavento e dello Scarpagnino al cantiere del Fondaco non provano tuttavia che essi ne fossero veramente gli architetti. È dunque preferibile pensare a un'opera di collaborazione in cui Hieronymus presentò un modello che prevedeva la decorazione almeno della facciata principale con un programma pittorico ambizioso, mentre i proti locali si limitarono a correggere, integrare e mettere in opera un progetto in cui alla fine non era più possibile distinguere una personalità ben definita. Ritengo tuttavia più probabile che sia stato Hieronymus e non lo Spavento a suggerire per primo l'idea di una grandiosa facciata dipinta e che questo fosse uno dei motivi per cui il decreto del 19 giugno 1505 prevedesse, oltre all'allineamento del prospetto con l'andamento del canale, l'asso- 
luto divieto di modificare il modello del tedesco.

Una seconda precisazione è tuttavia doverosa. Se l'idea della facciata dipinta può essere fatta risalire con le dovute cautele al maestro d'Oltralpe ciò non vuol dire che egli avesse mano libera nella scelta dei temi da affrescare, anche se come vedremo allusioni alle attività commerciali dei mercanti tedeschi non dovettero mancare. Il palazzo nei pressi dell'unico ponte della città e dirimpetto al mercato dei cambi era un luogo troppo esposto perché le autorità veneziane lo lasciassero decorare a piacere da una Nazione straniera, per quanto potente. Possiamo quindi essere certi che il governo veneziano esercitò un controllo assoluto sull'iconografia delle facciate dipinte dai due artisti provenienti dalla terraferma. Contrariamente a quanto accadde nel campo dell'architettura sembra che i pittori locali non dimostrassero alcun interesse per l'allogazione delle pareti da affrescare, forse perché avevano meno esperienza in questa tipologia dei colleghi provenienti dalla marca trevigiana e dal Cadore. Facciate dipinte erano assai diffuse a Padova come a Treviso, a Trento come a Verona, a Bassano come a Feltre e sono convinto che tanto Giorgione quanto Tiziano debbano avere realizzato imprese analoghe nei loro luoghi di origine ancor prima di cimentarsi sulle pareti del Fondaco poiché una sfida così impegnativa non avrebbe mai potuto essere portata a buon termine senza aver maturato una precedente esperienza in questo settore.

Prima di passare alle nostre prossime domande e al problema del programma iconografico, vorrei ribadire che il punto fondamentale della mia argomentazione non è quello di sostenere a tutti i costi la precedenza e una specie di leadership tedesca nel campo delle facciate dipinte. Può darsi che un giorno si rintraccino delle fonti più eloquenti dei dipinti del Bellini che provino l'esatto contrario. Quel che mi preme sottolineare è invece la convergenza di esperienze parallele fra mondo germanico e società veneta durante i primi due decenni del sedicesimo secolo. Non è in gioco il tentativo di accreditare un personaggio sostanzialmente anonimo con un'opera d'interesse storico eccezionale, bensì di ricostruire un clima culturale per poter apprezzare meglio il significato dell'operazione realizzata da Giorgione e da Tiziano.

\section{Il problema del "programma"}

Se accettiamo l'ipotesi che Hieronymus abbia progettato sin dall'origine una facciata historiata sul tipo di quelle che proprio allora si stavano affermando sui territori dell'impero, ci dobbiamo chiedere quale programma iconografico abbiano sviluppato i Veneziani per venire incontro ai desideri dei mercanti tedeschi. Ma come definire questo termine nel contesto di una tale tipologia? Di che cosa è lecito andare alla ricerca quando si discute del programma iconografico di una facciata dipinta e a quale pubblico si rivolgevano gli affreschi del Fondaco?

Notoriamente ilVasari (o chi per lui) fu incapace di comprendere l'iconografia del ciclo realizzato da Giorgione e dovremmo porci la domanda perché questo avvenisse. ${ }^{40}$ Come Jacob Burckhardt scrisse nel Cicerone: , Venedig besitzt in dieser Gattung nur noch Weniges und im Zustande fast totaler Zerstörung durch die Feuchtigkeit, aber von so grossen Meistern, dass man gerne auch die Trümmer aufsucht. So war der Fondaco de'Tedeschi am Rialto [...] vollständig bemalt von Tizian und seinen Schülern; hie und da ist noch ein schwacher Schimmer zu erblicken." 41 Burckhardt si dimenticò persino di citare il nome di Giorgione, ma riconobbe giustamente le facciate dipinte come un genere specifico e ci donò in una nota a piè di pagina un elenco eloquente dei pittori che, a detta delVasari, si erano distinti in questa "Gattung" 42 : vale a dire Vincenzo da San Gimignano, Baldassarre Peruzzi, Polidoro e Maturino, Taddeo Zuccaro, i Veronesi, Garofalo e i Lombardi e soprattutto Cristofano Gherardi detto il Doceno, la cui Vita risulta di particolare importanza per il genere pittorico sotto esame. Nella sua biografia il Vasari descrisse meticolosamente, tra l'altro, gli affreschi a chiaroscuro dipinti dall'artista nel 1554 sulla facciata del palazzo fiorentino di Sforza Almeni, il maggiordomo di Cosimo I, posto sulla via dei Servi. Ed è da un passo di questo tenore che possiamo dedurre oltre ogni possibilità di dubbio come il Vasari intendesse definire un programma iconografico per una facciata dipinta: diciamo subito che nella sua prospettiva avrebbe dovuto trattarsi di una struttura allegorica chiusa, vale a dire in sé coerente e autosufficiente, non suscettibile a variazioni o interventi esterni che ne alteras- 
sero in qualche modo il significato prefisso e preciso.

Il tema della decorazione elaborato dalVasari era nel caso del palazzo di Sforza Almeni "tutta la vita dell'uomo dalla nascita per infino alla morte," 43 ma esso si articolava a più livelli intorno alle aperture operate nella facciata. Il biografo scrive: "mise mano Cristofano alla detta facciata; nella quale [...] gli aiutò Giorgio, pregato da lui, a fare per le facciate alcuni disegni delle storie, disegnando anco talvolta nell'opera sopra la calcina di quelle figure che vi sono. Ma se bene vi sono molte cose ritocche dal Vasari, tutta la facciata nondimeno e la maggior parte delle figure e tutti gli ornamenti, festoni ed ovati grandi sono di mano di Cristofano. $[\ldots]$

Sono adunque in questa facciata tre spartimenti [vale a dire tre piani] [...] e sono [...] in ciascun finestrato sei finestre, che fanno sette spazi; e secondo quest'ordine fu divisa tutta l'opera per dirittura dalla cornice del tetto infino in terra. Accanto, dunque, alla cornice del tetto è in prospettiva un cornicione con mensole che risaltano sopra un fregio di putti, sei de' quali per la larghezza della facciata sono ritti, cioè sopra il mezzo dell'arco di ciascuna finestra uno, e sostengono con le spalle festoni bellissimi di frutti, frondi e fiori che vanno dall'uno all'altro; i quali fiori e frutti sono di mano in mano, secondo le stagioni, e secondo l'età della vita nostra, quivi dipinta. [...] Finita questa fregiatura, in fra i vani delle dette finestre di sopra, in sette spazi che vi sono, si feciono i sette pianeti con i setti segni celesti sopra loro, per finimento e ornamento. Sotto il davanzale di queste finestre nel parapetto, è una fregiatura diVirtù, che a due a due tengono sette ovati grandi; dentro ai quali ovati sono distinte in istorie le sette età dell'uomo" e via dicendo. ${ }^{44}$

La descrizione vasariana prosegue per diverse pagine, ma l'aspetto fondamentale è che nessun particolare della decorazione fu lasciato al caso: il programma iconografico si svolgeva intorno a un tema coerente affrontato a molteplici livelli cosicché persino elementi decisamente ornamentali come i fiori e i frutti impugnati dai putti rispettavano il ciclo di nascita, maturità, decadenza e morte dettato dal passare delle stagioni. Anche il dettaglio più minuto si piegava al concetto allegorico dominante $\mathrm{e}$ tutto girava intorno al numero sette, cioè al numero degli spazi fra le finestre creati dalle sei aperture nei piani alti del palazzo: sette pianeti, sette segni zodiacali, sette età della vita, sette virtù e le sette arti liberali. Una siffatta closure testuale, tanto amata dal Vasari, non era altrettanto diffusa al nord e non si fa fatica a capire come il biografo aretino, con una simile forma mentis, incontrasse serie difficoltà a decifrare il significato degli affreschi di Giorgione e di Tiziano, che a mio parere dovevano mostrare delle affinità maggiori con i temi ma soprattutto con l'articolazione delle facciate dipinte nell'Europa d'Oltralpe. Grazie a una ricco repertorio documentario, sia di fonti scritte che visive, sappiamo che i programmi iconografici sviluppati in quelle terre non erano organizzati di solito intorno a un unico tema, ma si dispiegavano in un intreccio di motivi iconografici in relazione più o meno diretta con la funzione del palazzo decorato, fosse esso una casa privata, un'osteria oppure la sede dell'amministrazione comunale.

Ed è partendo da questa premessa, dalla convinzione che gli affreschi del maestro di Castelfranco e di Tiziano avessero dei punti in comune con le facciate dipinte del mondo germanico, finendo così per creare dei grattacapi alla mente simmetricamente organizzata del Vasari, che propongo di riesaminare i lacerti e la documentazione tanto visiva quanto testuale del Fondaco dei Tedeschi, non per ricostruirne il probabile programma iconografico, che probabilmente non potrà mai essere recuperato integralmente in tutti i suoi dettagli, ma per farne rivivere almeno il carattere, o la tipologia se così dir si voglia. I dubbi da risolvere sono i seguenti: Giorgione e Tiziano hanno ricevuto dalla Signoria istruzioni precise? E se rispondiamo affermativamente, si trattava di un "programma" coerente nel senso inteso dal Vasari, benché egli stesso non fosse in grado di decifrarlo, oppure di una struttura "aperta"? Non meno interessante sarebbe poi stabilire se esistesse un nesso tematico fra le facciate affrescate dai due artisti, come è stato più volte suggerito ma mai dimostrato.

Commetteremmo tuttavia un errore se andassimo alla ricerca di una precisa fonte letteraria per l'iconografia delle due facciate, fosse essa a carattere biblico oppure mitologico. Persino ilVasari non avrebbe approvato una tale scelta. La logica interna di questo genere pittorico, per usare la terminologia messa in gioco da Burckhardt, non consente a una storia 
oppure a un mito preciso di distendersi liberamente sui diversi campi di una facciata. Gli artisti, come testimonia il passo del Vasari citato più sopra, sono invece partiti dal numero delle aperture sulla facciata e dalla conseguente organizzazione degli spazi da affrescare: quando la distribuzione di porte e finestre metteva a disposizione sette campi, questi venivano decorati con le virtù teologali e cardinali, con le arti del Trivio e del Quadrivio oppure con i sette pianeti (indimenticabile resta a questo proposito la definizione manieristica del Lomazzo secondo cui le facciate dipinte sarebbero state i luochi della luna, non solo perché su questi spazi erano concesse invenzioni capricciose e ghiribizzose ma anche perché queste pareti venivano decorate spesso con le immagini dei pianeti). ${ }^{45}$ Quando i riquadri a disposizione erano nove - come, per inciso, al Fondaco dei Tedeschi quale lo vediamo oggi vi si potevano dipingere le Muse, se dodici ci si sarebbe potuti rivolgere alle Fatiche d'Ercole, ma in nessun caso, a quanto mi consta, venne illustrato un episodio mitico specifico i cui protagonisti erano rappresentati nei diversi spazi o nelle nicchie di una facciata dipinta. Ciò avrebbe contraddetto le regole del genere, benché a volte esistessero delle combinazioni più complesse di quelle dettate dalla logica dei numeri.

Partendo da queste considerazioni non desidero tuttavia sostenere per un solo istante l'idea di una decorazione esclusivamente ornamentale, realizzata esclusivamente "per mostrar l'arte", come avrebbe detto il Vasari, e priva di qualsiasi messaggio da trasmettere attraverso l'iconografia della facciata. La semplicità delle scelte operate dagli artisti e dai loro committenti, spesso dettata da condizioni di carattere pratico, non impediva di progettare, pur partendo da questi vincoli, un disegno di una certa complessità tematica. Lo stesso Vasari ricordava che il Fondaco si trovava "nel più bel luogo e ne la maggior vista di quella città" 46 ed è pertanto difficile credere che gli affreschi di Giorgione e di Tiziano non avessero nulla da comunicare al loro pubblico. Al contrario, altri esempi della regione alpina confermano come programmi per facciate dipinte venissero addirittura redatti da umanisti che ne chiedevano l'approvazione ai committenti, mentre le numerose facciate di Trento, Verona e altre città tuttora decorate con ambiziosi cicli deco- rativi confermano l'esistenza di precise esigenze di propaganda politica o di promozione sociale oppure di tutte queste cose insieme. Vediamone alcuni esempi.

Il Palazzo Geremia in contrada larga a Trento, eretto da Giovanni Antonio Pona all'inizio del Cinquecento, è impreziosito da una facciata dipinta (fig. 2) in onore dell'imperatore Massimiliano che aveva nobilitato il committente per premiarne i sostanziosi aiuti finanziari alla corona. Enrica Cozzi ha studiato a fondo l'iconografia del ciclo ed è giunta alla conclusione che esso venne realizzato verso lo scadere del primo decennio, intorno al 1508$09,{ }^{47}$ contemporaneamente o poco dopo la decorazione del Fondaco dei Tedeschi a Venezia. Il secondo piano è decorato con una finta loggia da cui si affacciano agli angoli personaggi di alta estrazione sociale rappresentati nel giorno dell'entrata trionfale dell'imperatore a Trento, in occasione della sua incoronazione nella cattedrale della città, avvenuta l'otto febbraio $1508{ }^{48}$ ai lati della quadrifora, al di sopra dello stemma di famiglia affrescato al centro della seconda fascia marcapiano, sono invece dipinti due ritratti di Massimiliano colto nel momento di concedere udienza ai cittadini. Queste scene sono accompagnate da iscrizioni riportate nel fregio sottostante; molte di esse sono oggi purtroppo scomparse ma in un cartiglio si leggono chiaramente le parole seguenti: Maximilianus omnibus aures benigne prestat. Al piano nobile sono affrescati, sulla destra, tre fatti di storia romana come exempla di virtù civica: partendo dalla destra, un'azione concitata di solito identificata come suicidio di Lucrezia, Muzio Scevola che brucia la propria mano sul fuoco di fronte a Porsenna e Marco Curzio, uno dei temi preferiti nella lunga tradizione delle facciate dipinte per gli audaci scorci prospettici consentiti dall'episodio cruciale della sua biografia. ${ }^{49}$ Poiché $i$ tre atti eroici esaltano il tema del sacrificio a difesa della patria e dell'onore, essi sono affiancati, sulla sinistra, da una leggenda collegata tuttavia a un evento storico quasi coevo che ancora una volta sottolinea il tema della virtus civica, vale a dire lo strangolamento di un leone alato, simbolo della Repubblica di San Marco, da parte del cavaliere Jörg Senftel von Ebenstein, comandante delle milizie trentine alla battaglia di Calliano del 10 agosto 1487 . Un atto rappresentato di 


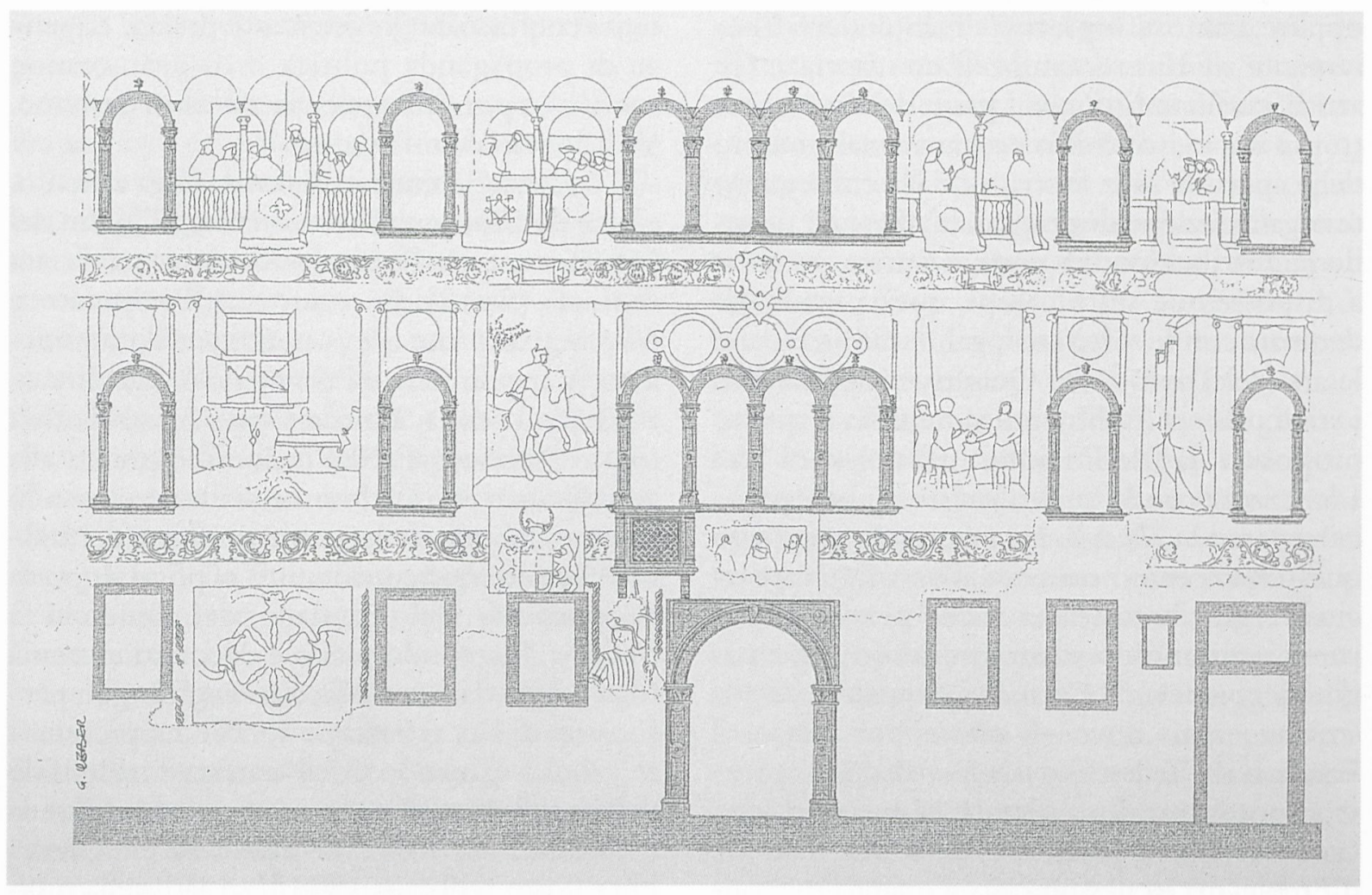

Fig. 2. Grafico degli affreschi sulla facciata di Palazzo Pona-Geremia a Trento (da Cozzi, Enrica, Programmi iconografici sulle facciate dipinte a Trento fra Quattro e Cinquecento, in: a cura di Castelnuovo, Enrico, Luochi della luna. Le facciate affrescate a Trento, Trento 1988).

fronte a un gruppo di magistrati che impersonano la giustizia. La battaglia di Calliano fu un evento traumatico nella storia della Serenissima, le cui truppe vennero umiliate in una sconfitta senza precedenti, e non era un segreto che Trento venisse considerata agli inizi del sedicesimo secolo come una città appartenente all'Impero. ${ }^{50} \mathrm{Se}$ pertanto la decorazione della facciata ci si presenta a un primo sguardo come un coacervo di temi ed episodi slegati fra loro di storia antica, recente e contemporanea, a un'analisi più approfondita essi si rivelano invece come un sistema di satelliti ruotanti intorno alla dichiarazione di fedeltà politica all'imperatore da parte dei proprietari. La virtù civica evocata da ben scelti episodi di storia romana, il valore delle forze armate locali al servizio della causa imperiale e la magnanimità dell'Imperatore s'intrecciano in un programma ben congegnato di aspirazioni politiche e orgoglio personale per il prestigio raggiunto dal committente sul piano economico e sociale. ${ }^{51} \mathrm{Ma}$ non si deve assolutamente dimenticare che la parte inferiore della facciata è decorata con una ruota della fortuna, da una ma forse in origine due imponenti figure di soldati ai lati del portone e da un affresco votivo sopra il portale d'ingresso rappresentante la Madonna col Bambino fra i santi Giovanni Battista e Antonio Abate. Anche in questo caso, a un primo sguardo, non sembra esistere una relazione precisa con gli altri dipinti della facciata, ma il contrasto fra la virtù e la fortuna era un tema umanistico assai diffuso sin dai tempi del Petrarca, mentre i due santi erano eponimi del committente, Giovanni Antonio Pona. Ogni elemento della decorazione rivestiva pertanto un significato, direi che quasi nulla fosse lasciato al caso, ci troviamo di fronte in altre parole a un vero e proprio "programma", eppure il Vasari, se lo avesse visto, ne sarebbe rimasto inorridito. Né si stenta a immaginarne il disappunto se qualche abitante della città si fosse tolto il disturbo di illustrarglielo, al contrario di quanto accadde a Venezia dove nessuno era in grado, a quanto pare, di rivelargli il tema degli affreschi di Giorgione: ilVasari non avrebbe approvato l'e- 
terogeneità dei temi rappresentati a Palazzo Pona-Geremia e dopo tutto, per poter "leggerne" la facciata, bisognava e si deve tuttora essere informati sul nome del committente, su un episodio di storia locale rappresentato in modo inconsueto, sull'araldica della città e sul riconoscimento della fisionomia dell'imperatore. È difficile dire quanti stranieri sarebbero stati in grado di decifrarne il significato, ma questo non vuol dire che i Pona non avessero meditato a lungo sui temi da far rappresentare. Tradotto nei termini del nostro problema: benché molti ignorassero il significato dei dipinti di Giorgione ciò non dimostra l'assenza di un programma né che essi fossero stati eseguiti solo "per mostrar l'arte".

Se il ciclo di Palazzo Pona-Geremia documenta come al tempo della decorazione del Fondaco le facciate dipinte delle case fossero in grado di trasmettere messaggi politici e autocelebrativi attraverso la sovrapposizione di temi iconografici complessi ambiziosamente intrecciati benché indipendenti, un secondo esempio di un prospetto purtroppo scomparso rivela l'esistenza di programmi scritti al servizio di questo genere pittorico all'epoca e nella regione geo-politica di cui ci stiamo occupando. L'imperatore Massimiliano era così legato alla città di Augusta da essere spesso nominato nei dispacci diplomatici quale "Augsburger Bürgermeister" 52 e dalla sua corrispondenza con Conrad Peutinger (1465-1547) sappiamo che nel 1512 aveva già discusso personalmente con l'umanista più conosciuto della città il suo programma per la decorazione della facciata del Rathaus. ${ }^{53} \mathrm{Ma}$ come ricorda Bruno Bushart nella sua breve storia dell'arte augustana, il progetto venne realizzato più tardi:"nella sala grande del municipio in cui avevano luogo le riunioni del Reichstag furono inserite nel 1515-16 delle rosse colonne di marmo e si allargarono le finestre. Hans Burgkmair ne disegnò i vetri, Jörg Muskat intagliò i 'welschen Kindlein' [puttini romandi] per la sala del consiglio, Peutinger consegnò il programma figurativo della facciata esterna su cui si rappresentò la dinastia della maestà imperiale a partire dai [primi] sovrani e re [del Sacro Romano Impero] includendo i re di Spagna e Sicilia." 54

L'epoca di Massimiliano fu particolarmente favorevole alle facciate dipinte: sono molti i prospetti decorati in cui è coinvolto il nome dell'imperatore, da Vienna ad Augusta a
Innsbruck - centro per anni delle spedizioni militari imperiali contro la Repubblica di Venezia e dove i rilievi con scene di vita a corte insieme ai dipinti di due lanzichenecchi portabandiera con i vessilli decorati con l'aquila bicipite eseguiti da Jörg Kölderer sulla facciata del Goldenes Dachl risalgono ai primi anni del Cinquecento. ${ }^{55} \mathrm{Ma}$ per evitare qualsiasi equivoco, non ricordo questi fatti per mettere la Nazione tedesca e il Kaiser in un rapporto diretto con gli affreschi del Fondaco veneziano. La Serenissima non avrebbe mai tollerato un'interferenza così massiccia dall'esterno, soprattutto se teniamo presente che l'opera venne realizzata in tempi di alta tensione politica fra le due parti. Qui desidero solo ricostruire un clima culturale in modo da contestualizzare meglio l'impresa di Giorgione e di Tiziano. Il crescente disagio tra la Signoria e l'imperatore, mescolato però alle eccellenti relazioni commerciali, consigliava prudenza, circospezione, abilità diplomatica e disponibilità al compromesso. Il governo veneziano sapeva quanto i loro vicini apprezzassero le facciate dipinte istoriate, diffuse nel mondo d'Oltralpe almeno dal quattordicesimo secolo, ed è possibile che venisse incontro ai loro desideri anche se, come abbiamo visto, il genere era tutt'altro che sconosciuto in laguna. I committenti dovevano inoltre sapere che Massimiliano e il suo entourage le utilizzavano a volte a fini politici, ma è altamente improbabile che un ciclo affrescato in un luogo così esposto quale la facciata ai piedi del ponte di Rialto, centro internazionale di scambi economici, potesse trasmettere un chiaro messaggio politico. Gli eventi precedenti alla Lega di Cambrai dimostrano con quale velocità fosse possibile ribaltare le alleanze e sarebbe stato imprudente sostenere questo o quel partito con immagini di aperta propaganda politica.

La storia del genere in questa regione rivela invece come le connotazioni astronomiche e astrologiche godessero di un certo favore anche nel Veneto. Una storia degli affreschi del Fondaco non può prescindere pertanto dalla sua ricezione e in questa sede vorrei esaminare almeno il ciclo dipinto sulla facciata di casa Parma Lavezzola (figg. 3 e 4) a San Pietro Incarnario a Verona. ${ }^{56}$ Benché oggi rovinato, possiamo contare sulla stampa acquerellata di Pietro Nanin che documenta l'ottimo stato dell'opera poco dopo la metà del diciannovesi- 


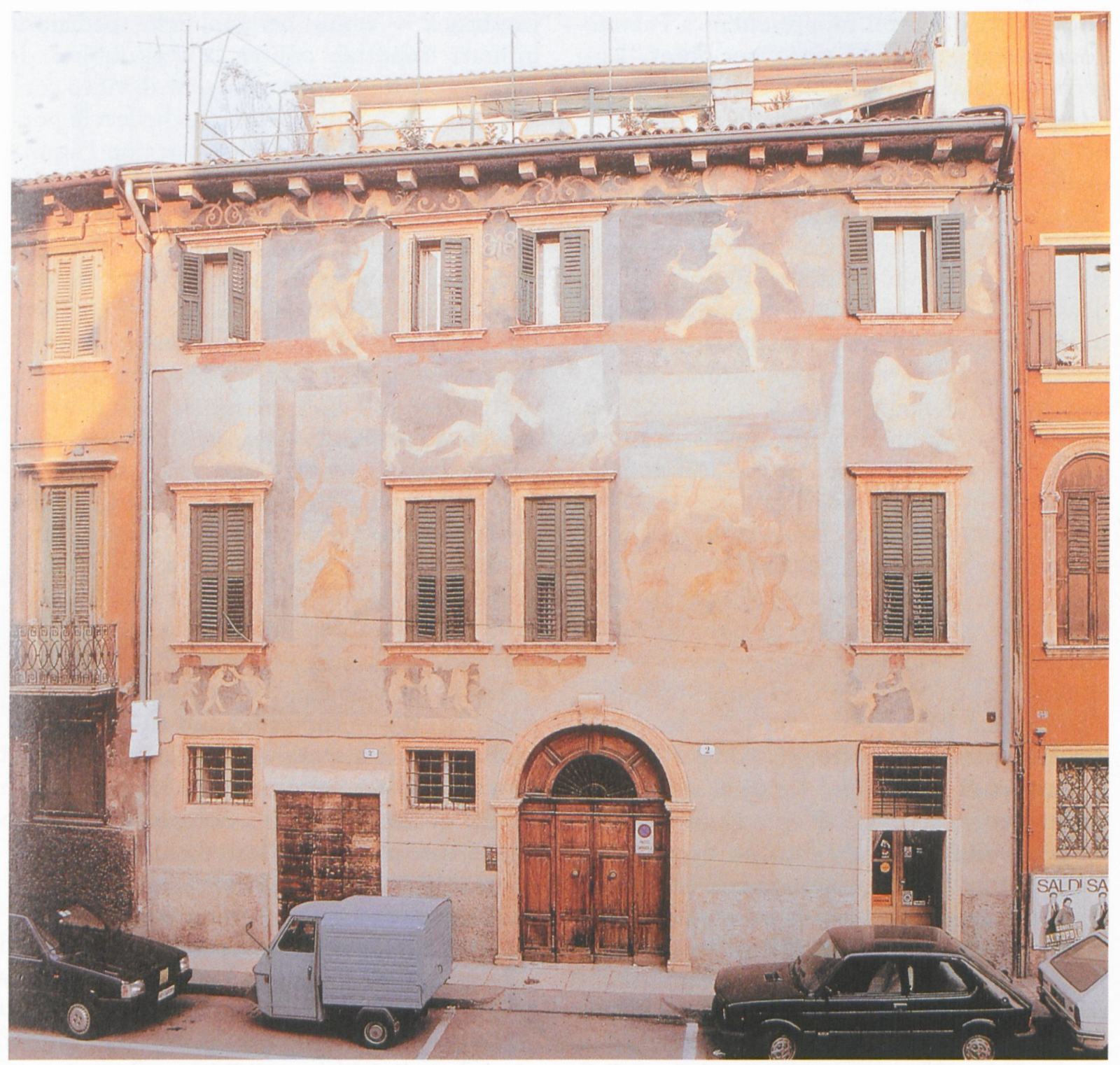

Fig. 3. Nicola Giolfino, Facciata della casa Parma Lavezzola a Verona.

mo secolo. ${ }^{57}$ Oltre alle personificazioni dei sette pianeti si scorgono, se seguiamo l'interpretazione di Gunter Schweikhart, la figura del saggio Tolomeo con un astrolabio e un compasso fra le mani nonché tre contadini che si agitano animatamente mentre un cagnolino scodinzola ai loro piedi: l'uomo sulla sinistra non gesticola in direzione del castello turrito seduto sulla cima del colle bensì verso la luna in fase calante. Le affinità con un dettaglio della facciata affrescata da Giorgione aVenezia sono in questo caso evidenti. Come ricordano le fonti, egli aveva dipinto sugli angoli alcune figure intente a misurare una sfera. Carlo Ridolfi ricorda che "ne' cantoni fece Geometri, che misurano la palla del Mondo," 58 mentre Anton
Maria Zanetti vi vide figure "di Filosofi che misurano un globo." ${ }^{59}$ Ed è quindi possibile che il ciclo possedesse connotazioni geografiche e/o astronomiche: già Giovanna Nepi Scirè aveva proposto di identificare la celebre $\mathrm{Nuda}$, resto malinconico della ricca decorazione di Giorgione, con una personificazione dell'astronomia o di un'altra arte liberale in base all'elemento sferico che essa sembra o comunque avrebbe potuto sostenere nella mano sinistra, giusta l'incisione dello Zanetti, ${ }^{60}$ un'idea condivisa da altri autori. ${ }^{61}$ Non mi risulta tuttavia che alcuno si sia spinto a identificare una parte - si badi bene, solo una parte - del ciclo con personificazioni o allegorie dei pianeti. Ed è quanto mi ripropongo di fare indirizzando 


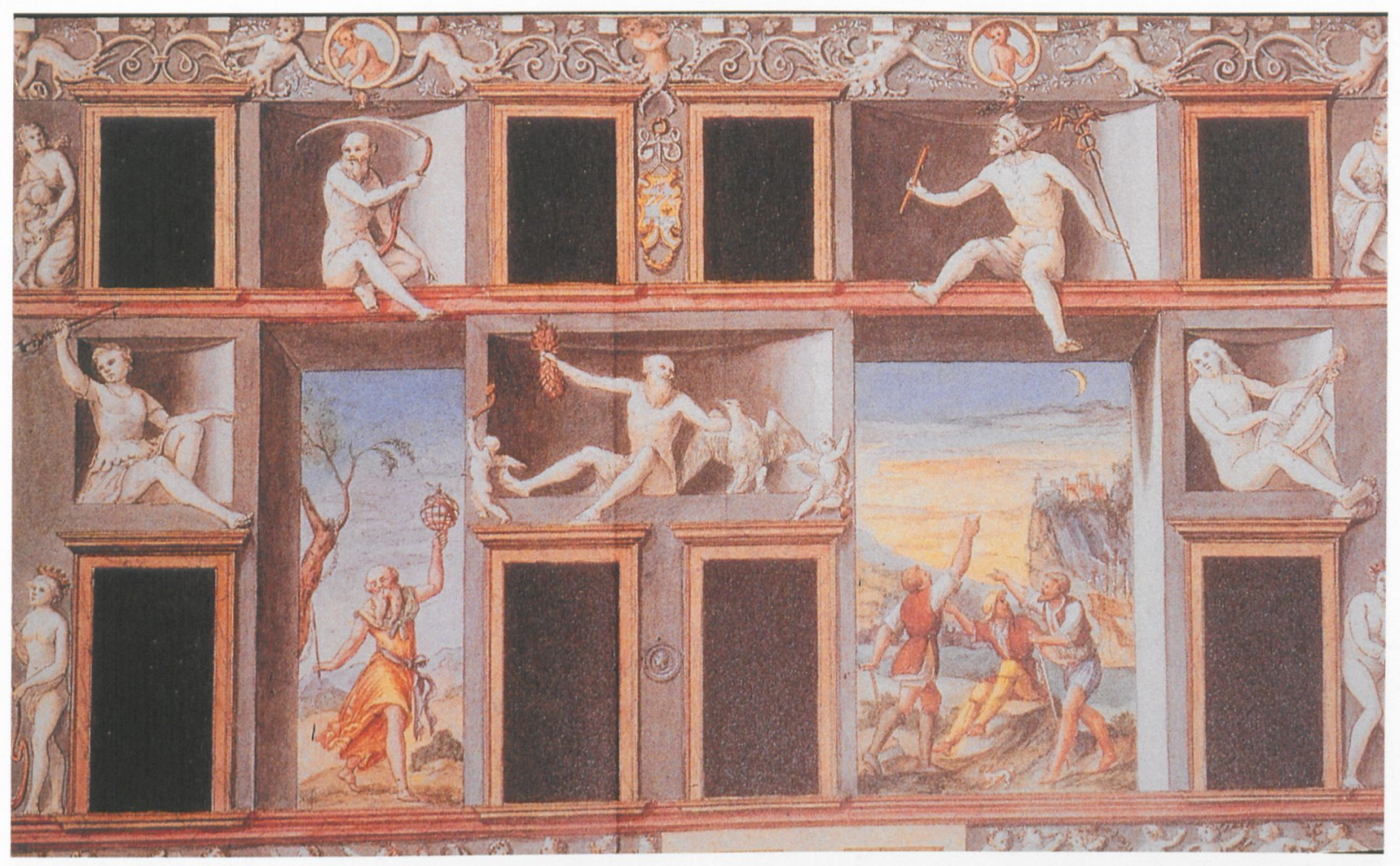

Fig. 4. Pietro Nanin, disegno acquerellato della facciata di casa Parma Lavezzola (da Nanin, Pietro, Disegni di varie dipinture a fresco in Verona, Verona 1864, tavole 35-36).

l'indagine verso il problema del pubblico, un tema sinora del tutto trascurato dagli studi sul Fondaco.

Poiché Rialto non era solo il centro commerciale di Venezia in cui gli uomini di Stato s'incontravano quotidianamente con mercanti, popolo e agenti di cambio, ma anche il luogo privilegiato (ancora per poco) del commercio mondiale rappresentato dalle colonie di uomini d'affari tedeschi, toscani e di altre Nazioni, la domanda può sembrare a un primo sguardo superflua. ${ }^{62} \mathrm{Ma}$ essa potrebbe essere riformulata nel modo seguente: qual era il pubblico privilegiato degli affreschi del Fondaco? Chi li fruiva quotidianamente? Allora come oggi masse di pedoni sono transitate sul ponte di Rialto, ma è probabile che solo pochi si siano chiesti, come fece il Vasari, quale fosse il significato delle figure monumentali rappresentate e ancora di meno devono essere stati coloro che potessero interpretarle in modo corretto. (Si pensi di nuovo al grado di competenza richiesto perché uno spettatore potesse decifrare il tema dei dipinti murali di palazzo Pona-Geremia a Trento.) Eppure qualcuno ha commissionato questo ciclo e altri lo avevano sotto gli occhi tutti i giorni, ma questo pub- blico privilegiato non era costituito dai mercanti tedeschi bensì dai magistrati veneziani impiegati sulla sponda del canale opposta al Fondaco. Questo spazio è oggi occupato dal palazzo dei Camerlenghi: prima dell'incendio del 1514 vi lavoravano tuttavia altri dipendenti dello Stato ed è giunto il momento di chiedersi chi fossero. 63

Oltrepassando il ponte di legno in direzione dell'isola di Rialto si ritrovavano i seguenti Uffici: sulla sinistra, nel luogo dove oggi sorge il Palazzo dei Dieci Savi ricostruito dallo Scarpagnino dopo l'incendio, operavano non solo i suddetti magistrati responsabili per la raccolta delle decime, ma anche i Provveditori sopra la revisione dei conti a cui era assegnato il compito di controllare le spese degli ambasciatori e delle alte cariche militari, i Provveditori sopra gli Uffici a cui era affidata la contabilità dei traffici con l'isola di Cipro, i Sindaci di Rialto e altre piccole magistrature oltre a una prigione al pian terreno. Proseguendo a sinistra sulla Riva del Vino ci s'imbatteva nella sede dei Provveditori al sale, vale a dire della magistratura cui spettava la ricostruzione del Fondaco e della sua decorazione. ${ }^{64} \mathrm{E}$ qui sia ricordato di sfuggita che solo uno di questi ufficiali era direttamen- 


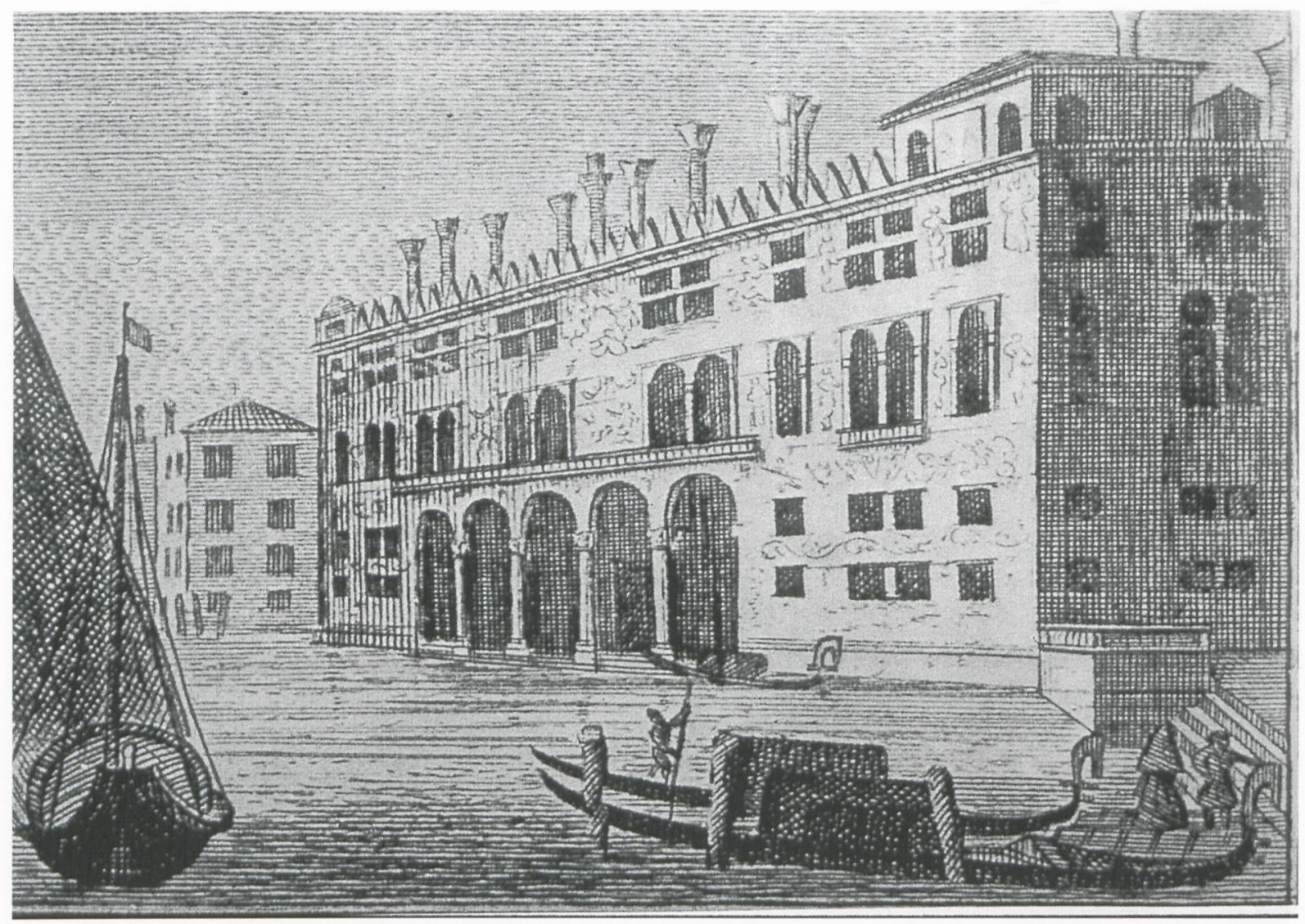

Fig. 5. Il Fondaco dei Tedeschi nell'incisione del Forestiere illuminato dell'Albrizzi.

te responsabile per questi lavori: nell'anno 150506 il compito venne svolto da Piero Lando, in quello successivo da Marco Tiepolo e nel 150708 da Alvise Sanudo. ${ }^{65}$ Ciò non significa che il committente di Giorgione vada identificato in Marco Tiepolo oppure in Alvise Sanudo: alcu-ni studiosi ritengono che il ruolo dei Provveditori sia stato sopravvalutato e altri hanno chiamato in causa la figura del doge Leonardo Loredan a cui l'artista, stando alla testimonianza del Vasari e del Ridolfi, avrebbe dipinto il ritratto. $\grave{E}$ invece probabile che il programma del ciclo fosse approvato da un consiglio investito di una grande autorità quale il Collegio, a cui era già stata data l'ultima parola sui modelli architettonici presentati al concorso, ed è certo che nell'arco del 1507-08 Giorgione ebbe a che fare direttamente con Alvise Sanudo per la disputa sul suo compenso. ${ }^{66}$

In questo caso tuttavia conoscere chi abbia di fatto firmato il contratto o, con maggiore probabilità, solo l'accordo con l'artista per la decorazione delle pareti del Fondaco è pres- soché irrilevante poiché si trattò quasi di sicuro di una decisione collettiva sancita dal Collegio. Molto più interessante è chiedersi invece quale ruolo possano aver giocato le aspettative dei fruitori privilegiati in questo spazio pubblico e all'aperto, soprattutto quelle dei magistrati residenti dirimpetto al Fondaco, i cui edifici si trovavano sulla destra una volta oltrepassato il ponte di legno in direzione dell'isola di Rialto. I documenti raccolti dalla Calabi e dal Morachiello restituiscono la vita alle tre strutture documentate nella veduta di Jacopo de' Barbari, cadute vittime dell'incendio devastante del 1514. I cinque Savi alla Mercanzia, il cui compito era la ricomposizione delle controversie sorte nell'ambito del commercio internazionale, svolgevano il proprio lavoro sotto una loggia aperta: l'ambiente era frequentato da uomini d'affari e questo pubblico avrebbe visto volentieri immagini alludenti al denaro, alle finanze, al commercio e alla giustizia. Il secondo edificio ospitava i magistrati delle Razon vechie istituite per amministrare le spese degli ambasciatori stra- 
nieri ospiti della Serenissima. A questo pubblico non sarebbe dispiaciuto ammirare temi inneggianti al commercio, al benessere e forse alla pace. Di fianco agli ufficiali delle Razon vecchie operavano i Camerlenghi, i custodi dei forzieri dello Stato, mentre in una loggia posta dietro il loro edificio risiedevano gli impiegati alle Razon nuove che controllavano i conti degli ambasciatori veneziani inviati all'estero. ${ }^{67}$ Anche costoro, alla pari dei Camerlenghi, avrebbero apprezzato personificazioni o episodi legati al commercio, al danaro e ai metalli preziosi, come oro e argento, da cui si coniavano le monete.

Chiarite le possibili aspettative di questo pubblico privilegiato, non possiamo però che appellarci alle avare fonti visive giunte sino a noi per verificare l'attendibilità di queste ipotesi, in particolare alla celebre incisione che accompagna molte edizioni settecentesche del Forestiere illuminato dell'Albrizzi e a una veduta, inedita in questo contesto, attribuita senza fondamento al Bellotto ma assai interessante dal punto di vista documentario. ${ }^{68}$ Malauguratamente l'incisione (figg. 5 e 6) è troppo generica e imprecisa per costituire un documento storico credibile, ma ci dice di più di quanto non si sia propensi ad ammettere: le fasce a girali di fianco al portico d'attracco per le gondole devono essere esistite per davvero e il fregio di putti danzanti in corrispondenza degli archi fa parte del repertorio delle facciate dipinte; le figure monumentali in contrapposto, forse ignude, fra le finestre del piano superiore potrebbero riflettere la realtà dato che la Nuda dell'Accademia proviene da uno spazio immediatamente sotto il cornicione, posto fra la quinta e la sesta finestra da sinistra. ${ }^{69}$ Inoltre in alto a destra si scorge una figura dall'ampia veste che potrebbe corrispondere a uno dei "filosofi" o "geometri" ricordati dalle fonti sui cantoni del palazzo per la somiglianza con l'abbigliamento del cosiddetto Tolomeo sul prospetto di casa Parma-Lavezzola a Verona. E per concludere non mi sentirei di mettere da parte sbrigativamente l'episodio o i due episodi narrativi schizzati in mezzo alla facciata. Di solito si ripete che l'incisione è particolarmente fantasiosa proprio perché questo dettaglio e la distribuzione delle balconate con le balaustre è del tutto diversa da ciò che vediamo oggi. Ma mi chiedo se siano stati eseguiti dei sondaggi attendibili sulla muratura del

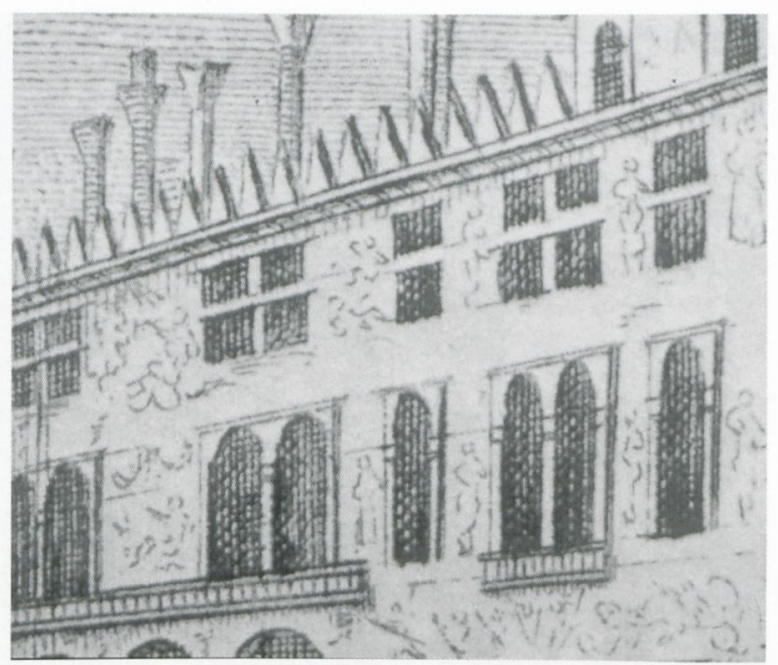

Fig. 6. Dettaglio della figura 5.

Fondaco, se non si possa in qualche modo stabilire che l'edificio venne alterato proprio in questa parte prima degli interventi ottocenteschi e dei restauri del secolo che si è appena concluso. ${ }^{70}$ Anche Sandra Rossi, nella scheda del catalogo alla mostra di Giorgione, accennava a questa possibilità benché il dipinto della Pinacoteca Comunale di Ascoli (figg. 7 e 8), che ha il carattere di una documentazione accurata e non di fantasia, sembri eliminare qualsiasi dubbio in proposito. ${ }^{71}$

Se riconsideriamo il problema del pubblico, possiamo tuttavia formulare qualche ipotesi perché solo così potremo far progredire gli studi su questo tema confrontando tesi da confermare e da smentire: nel nostro caso l'immaginazione dello storico non è solo permessa bensì richiesta. E se il lettore avesse ricoperto la carica di uno di quegli ufficiali che ogni giorno si recavano al lavoro nella zona rialtina non avrebbe salutato con piacere un Pantheon di divinità legate all'oro, come Apollo il padre delle Muse, o al commercio, come Mercurio già immortalato nella veduta panoramica della città incisa da Jacopo de' Barbari? Si potrebbe ribattere che si tratta di ipotesi prive di ogni fondamento, ma non si dovrebbe dimenticare che le divinità dell'Olimpo erano da lunga data associate ai pianeti e che la filosofia dell'alto Medioevo aveva messo sette tipi di metalli in relazione diretta con i corpi celesti: l'oro (aurum) con il Sole o, in altri termini, Apollo; l'argento (argentum) con la Luna simboleggiata da Diana, 


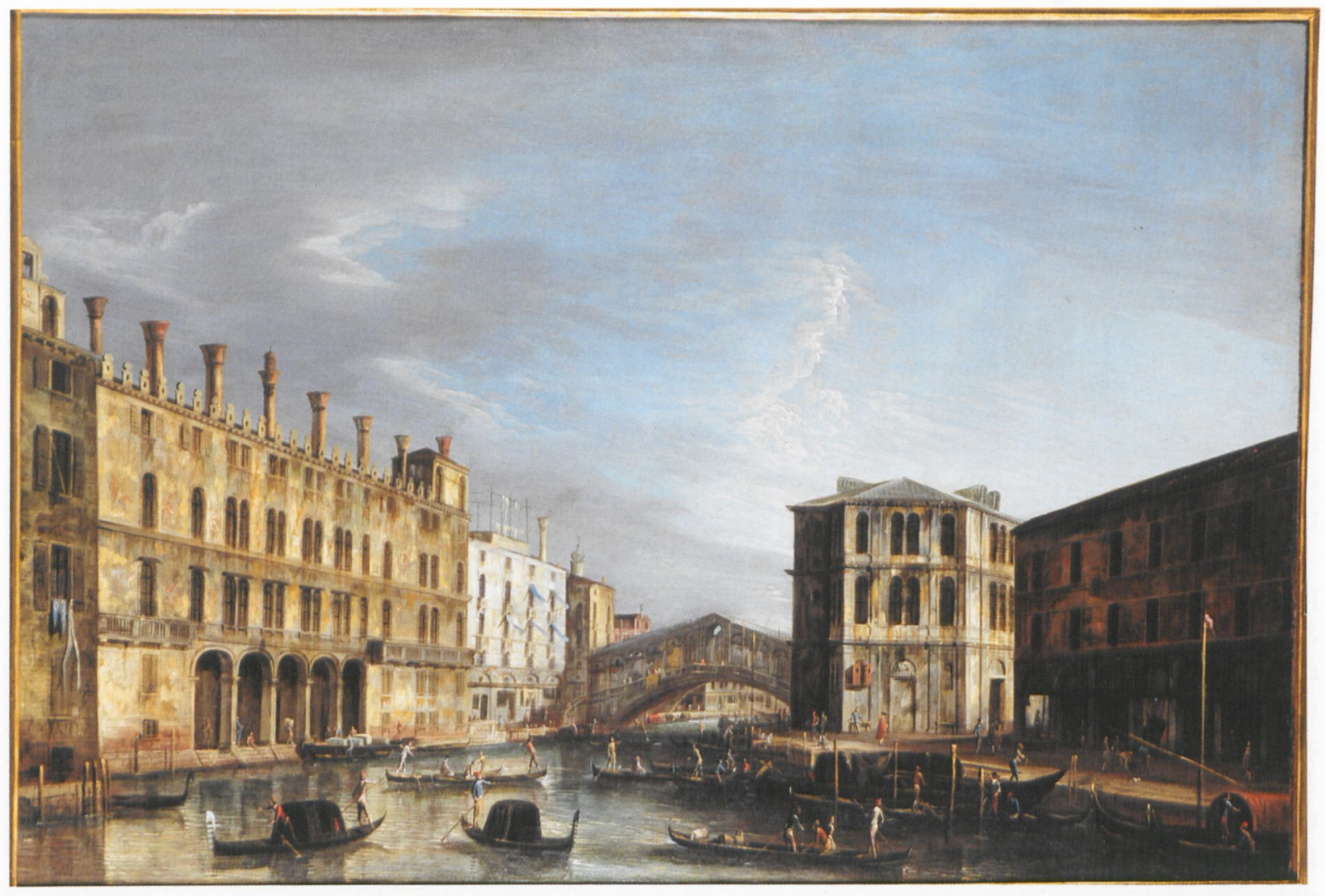

Fig. 7. Anonimo Veneziano del XVIII secolo, Veduta del Canal Grande con il Fondaco dei Tedeschi. Ascoli Piceno, Pinacoteca Comunale.

sorella di Apollo; il piombo (plumbum) con Saturno; il rame (cuprum) con Venere; lo stagno (stagnum) con Giove; il ferro (ferrum) con Marte e il mercurio (argentum vivum) con la divinità omonima. ${ }^{72}$

Chiediamoci ora quali materie prime abbiano esportato i mercanti tedeschi sul mercato di Rialto e troveremo la risposta nei metalli, soprattutto rame e argento, ma non solo. Cito da Gino Luzzatto, uno dei grandi storici dell'economia dell'età moderna molto attento alla scena veneta: "Nel seno della borghesia artigiana [dell'area del Basso Reno intorno ad Augusta, Norimberga, Ratisbona, Passau e Vienna] gli elementi più audaci [della società] sono indotti ad impiegare una parte dei capitali in operazioni finanziarie, e trovano per questo un'occasione particolarmente favorevole nelle necessità urgenti di cassa in cui si trovavano i principi tedeschi e in particolare l'imperatore, nel periodo in cui le guerre condotte dai mercenari sono diventate costosissime. [...] Le operazioni finanziarie dei ricchi borghesi di Augusta, di Ulma o di Norimberga $[\ldots]$ hanno importanza $[\ldots]$ soprattutto per i diritti di esclusiva nella vendita dei metalli o per la concessione dello sfruttamento delle miniere. L'industria mineraria e il commercio dei metalli costituiscono appunto negli ultimi decenni del Quattrocento e nella prima metà del Cinquecento il ramo più importante dell'economia dei paesi soggetti a Casa d'Austria. La produzione dell'argento, entro i soli confini del Sacro Romano Impero di nazione germanica, supera, fino al 1545, quella di tutti gli altri paesi della terra. Ma anche maggiore era la superiorità della Germania per gli altri metalli, specialmente per il rame. [...] Lo sviluppo rigoglioso dell'industria mineraria che, oltre all'argento ed al rame, si estende al piombo, allo stagno, al ferro, al mercurio ed anche - sebbene in quantità assai modeste - all'oro" assicura a tutta l'economia tedesca uno sviluppo straordinario. ${ }^{73}$ Lo storico dell'economia elenca quindi i sette metalli che ormai per tradizione erano direttamente collegati ai pianeti e con questo tema, forse proposto dall'"architetto" Hieronymus per essere adatto al genere dei luochi della luna, avrebbero potuto sentirsi a proprio agio anche i Provveditori al Sale e gli altri magistrati impegnati giorno dopo giorno in operazioni 


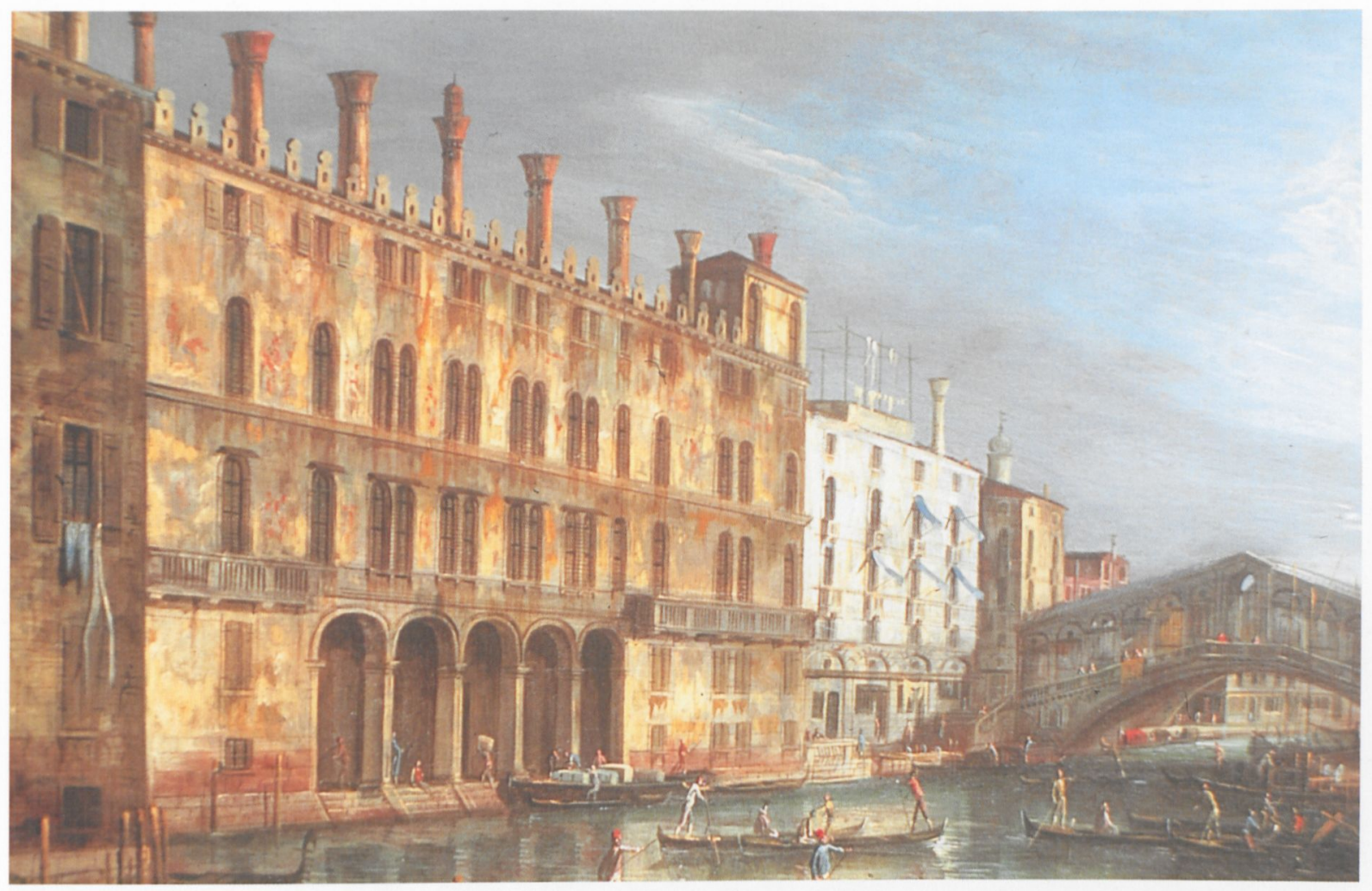

Fig. 8. Particolare della figura 7.

finanziarie nonché gli agenti di cambio insediati sulla riva opposta del canale. ${ }^{74}$

La proposta sembra particolarmente adeguata agli interessi se non alle esigenze dei mercanti e degli addetti alle attività bancarie, mentre gli ambasciatori che si rivolgevano agli ufficiali delle Razon vecchie per ottenere i panni e le suppellettili per adornare lussuosamente le stanze a loro riservate in qualche palazzo veneziano avrebbero inoltre apprezzato il messaggio di pace trasmesso dal leone alato della Repubblica. Un dipinto del Canaletto (fig. 9) oggi nel Sir John Soane's Museum di Londra ${ }^{75}$ e il corpus delle iscrizioni veneziane del Cicogna dimostrano come le due torreselle agli angoli del Fondaco, purtroppo demolite nell'Ottocento, fossero decorate con leoni scolpiti affiancati in origine da queste parole: PRINCIPATVS LEONARDI / LAVREDANI INCLYTI / DVCIS ANNO SEXTO. ${ }^{76}$ I leoni accompagnati dalle iscrizioni erano gli unici elementi in comune fra le due facciate poiché anche l'ingresso da terra - che secondo GiorgioVasari e Francesco Sansovino costituiva l'entrata principale mentre nella letteratura moderna è descritto spesso quale portone late- rale o secondario ${ }^{77}$ — era sormontato da un leone alato che sosteneva un libro aperto con il motto PAX TIBI MARCE (fig. 10)..$^{78}$ È molto probabile che questo motto fosse scolpito anche sui volumi ai piedi dei leoni della facciata sul canale e che quindi il "programma" iconografico di questo prospetto fosse coronato da un augurio di pace a favore della prosperità dei commerci della Serenissima e dei suoi ospiti.

Tuttavia, questo tentativo di ricostruzione non può che rimanere frammentario. Se Hieronymus elaborò veramente un program$\mathrm{ma}$ in cui le personificazioni dei pianeti associate alle figure di "geometri" intenti a misurare un globo avrebbero potuto svolgere un ruolo dominante, resta il fatto che Carlo Ridolfi e Giovanni Bartolomeo Milesio, le fonti scritte di maggior peso nella ricostruzione degli affreschi perduti di Giorgione, ricordino altri dettagli da spiegare. Ridolfi scrive: "[Giorgione] divise trofei, corpi ignudi, teste à chiaro scuro; e ne' cantoni fece Geometri, che misurano la palla del Mondo, prospettive di colonne e trà quelle huomini à cavallo et altre fantasie." ${ }^{\prime \prime 9} \mathrm{~A}$ detta del Milesio questi colonnati di ordine 


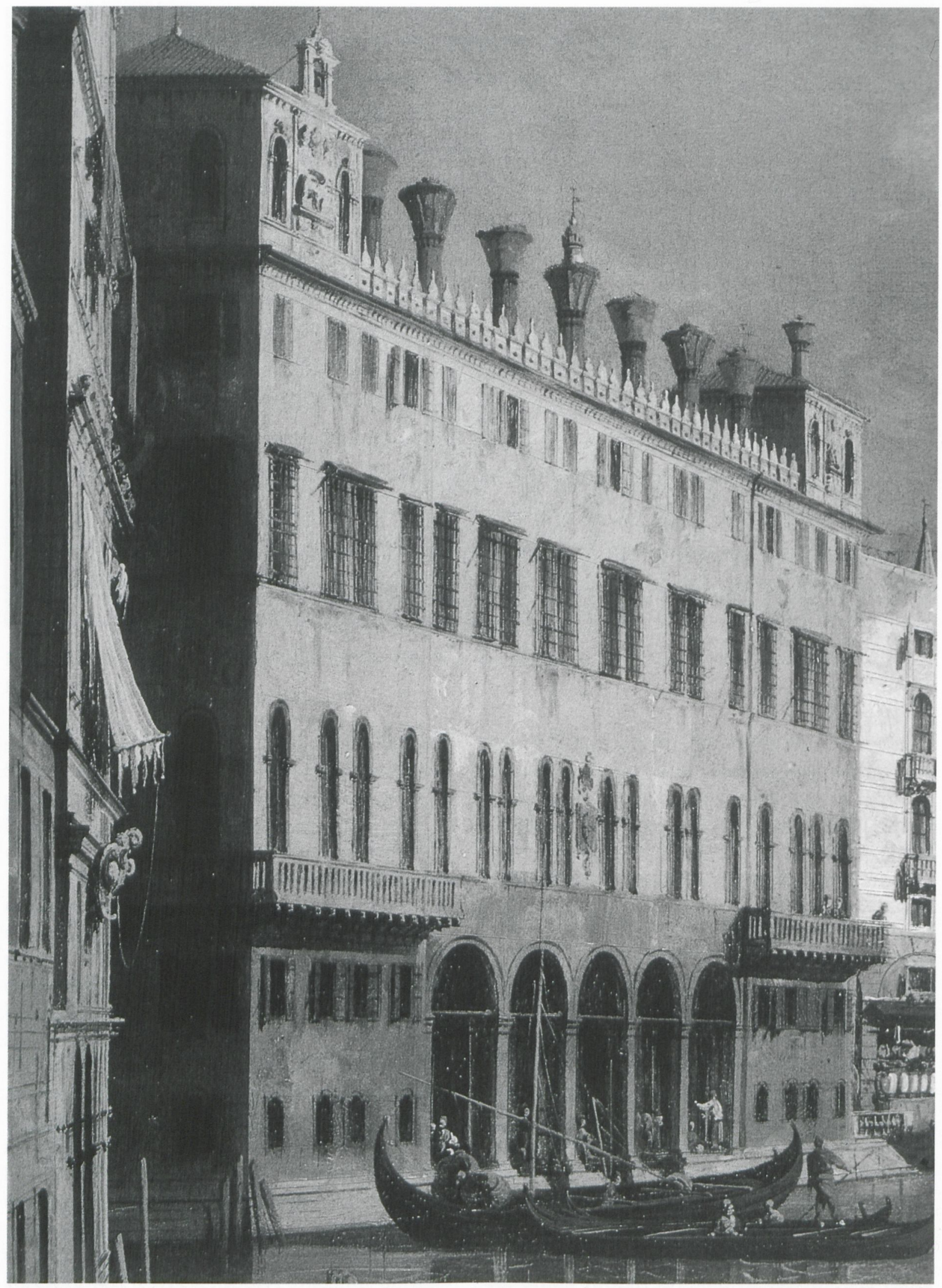

Fig. 9. Canaletto, Veduta del Canal Grande con il Fondaco dei Tedeschi (particolare). Londra, Sir John Soane's Museum. 
corinzio si trovavano sia al centro della facciata e sia davanti alle due sale, vale a dire ai due refettori posti agli angoli del piano nobile, aggiungendo che le eleganti figure colorate erano finte all'interno di singole nicchie. ${ }^{80}$ In effetti il dipinto della Pinacoteca di Ascoli (fig. 8) sembra confermare queste descrizioni: nei due piani superiori sono chiaramente visibili alcune figure, forse finte statue in nicchie, mentre all'angolo sinistro del piano nobile si scorge con qualche sforzo un cavaliere su un destriero impennato e, al di sopra della finestra, i frammenti di quattro colonne. Sembra quindi che il Ridolfi riferisse il vero quando ricordava degli uomini a cavallo fra queste prospettive e benché non sia chiaro a cosa alludessero, se non vogliamo arrenderci alla spiegazione riduttiva del "mostrar l'arte", dobbiamo lasciare aperta la via di altri temi collegati alla glorificazione della ricchezza e del commercio attraverso le personificazioni dei pianeti. ${ }^{81}$ Si pensi di nuovo all'intreccio complesso degli affreschi di casa Pona-Geremia a Trento: al soggetto principale della virtù civica si affiancavano il tema umanistico del rapporto virtù-fortuna e l'esaltazione del nome del proprietario attraverso la rappresentazione di due santi eponimi. Propongo una soluzione analoga per la facciata d'acqua del Fondaco: Giorgione avrebbe potuto dipingere una serie di personificazioni dei pianeti sotto la protezione del pacifico leone marciano, ma ciò non vuol dire che all'artista e ai suoi committenti non fosse concesso di elaborare dei sottotemi, come la natura di questo genere pittorico permetteva e persino richiedeva.

Resta tuttavia da chiedersi perché ilVasari (o chi per lui) non fosse in grado di "leggere" il programma quando persino la facciata per Sforza Almeni era in parte decorata con allegorie dei pianeti. Credo che si possano immaginare tre scenari, al di là di una semplice malignità interessata o di una pigrizia intellettuale pur sempre possibile: 1) può darsi che si sia trovato di fronte a personificazioni inusuali dei pianeti, a immagini ispirate dalla grafica norditaliana senza paragoni con la tradizione fiorentina; 2) è inoltre possibile che, scrivendo a più di quarant'anni dall'esecuzione del ciclo, si fossero persi nel frattempo alcuni attributi iconografici utili a identificare con maggiore precisione le personificazioni; 82 3) ma sono convinto che il Vasari sia stato soprattutto sor-

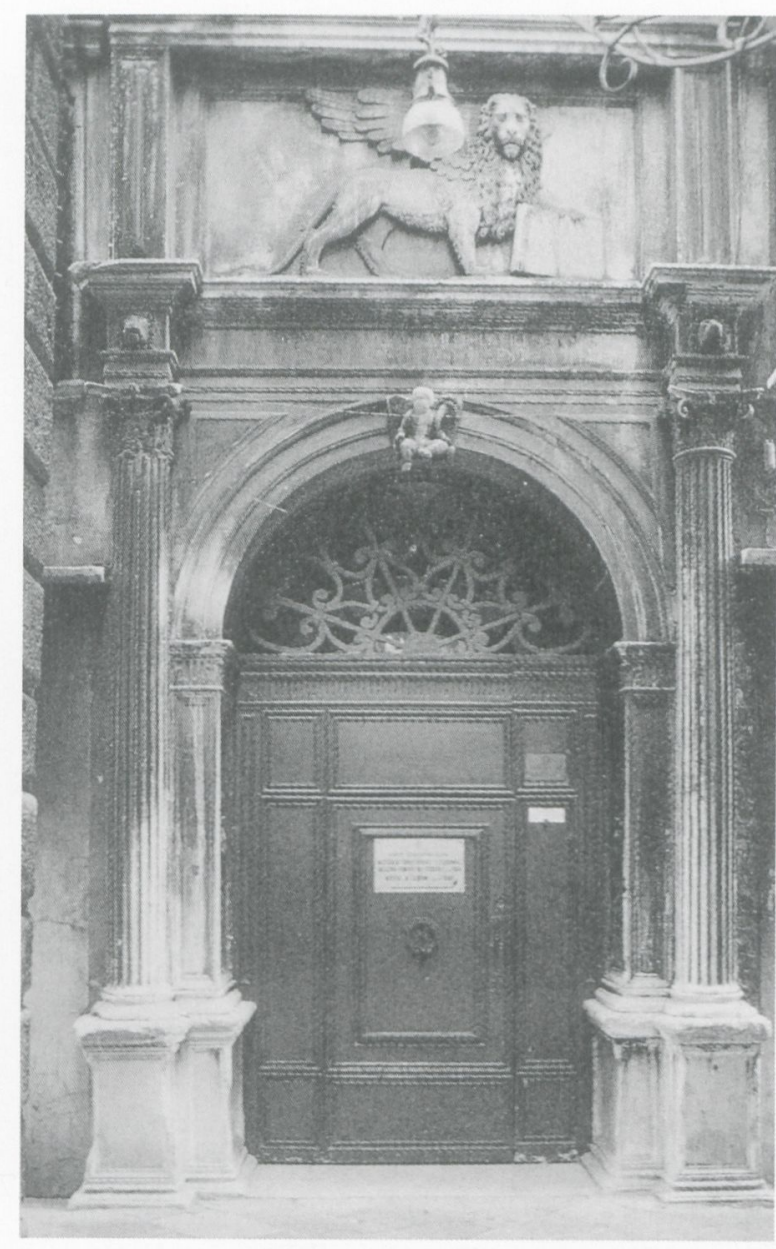

Fig. 10. Portale d'ingresso del Fondaco dei Tedeschi.

preso e sviato da una struttura iconografica estranea alla propria forma mentis. Là dove la cultura dell'Italia centrale privilegiava una struttura chiusa e ingessata del concetto, si rispondeva a nord con una maggiore flessibilità di temi non privi tuttavia di una loro coerenza tematica.

\section{Il ciclo di Tiziano}

Resta da analizzare brevemente il ciclo dipinto da Tiziano sul lato delle Mercerie, meritevole di uno studio specifico in altra sede. I frammenti superstiti e le testimonianze grafiche sono in questo caso comunque più numerose e l'argomentazione può procedere pertanto in modo più spedito, partendo tuttavia da due premesse tuttora da dimostrare: benché eseguite di fatto negli stessi anni, le immagini dipinte da Tiziano appartengono, per uno scarto di pochi mesi, a un momento storico caratterizzato da 


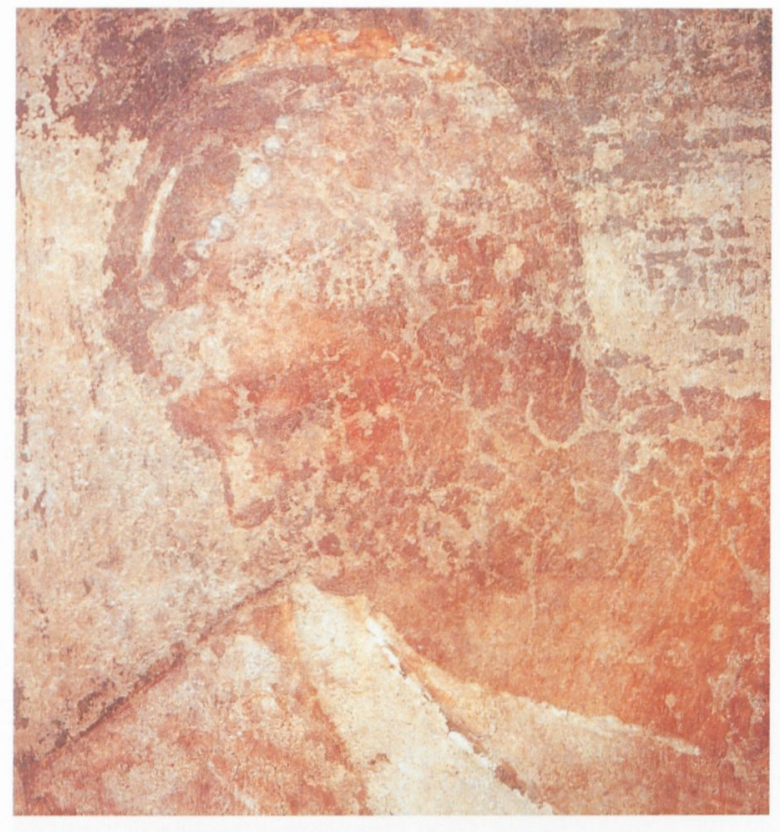

Fig. 11. Tiziano, Giuditta/Giustizia, particolare. Venezia, Galleria Giorgio Franchetti.

un clima politico leggermente diverso, uno dei motivi per cui non hanno alcun rapporto iconografico con quelle affrescate da Giorgione; inoltre esse vennero realizzate per un altro pubblico. Mi sia concesso, per alleggerire l'apparato filologico, di non ripercorrere tutti i passaggi che mi hanno condotto a elaborare la ricostruzione proposta qui di seguito: sia sufficiente dire che la documentazione di questo ciclo viene riesaminata in un nuovo contesto per offrire un panorama in gran parte inedito anche perché riletta, una volta di più, dal punto di vista del pubblico.

Chi si avvicinava al palazzo dalla parte di terra, come di certo facevano spesso i mercanti tedeschi, ma non solo, veniva salutato in origine dalla bellicosa Giuditta affrescata da Tiziano sopra una bifora del piano nobile in corrispondenza del portone d'ingresso disegnato dallo Scarpagnino (figg. 11 e 12). A lungo si è discusso sul significato di questa figura, che il Vasari aveva identificato dubitativamente benché assai poco plausibilmente con una Germania "quasi in forma d'una Iuditta," 83 e da allora si è andata sempre più affermando l'idea che questa eroina discinta, con un piede calcato sulla testa mozzata di Oloferne e sguainante minacciosa la spada della Giustizia di fronte al volto di un soldato, agisse come un monito politico durante i mesi turbolenti che accompagnarono la nascita della Lega di Cambrai. ${ }^{84}$

Lo storico dell'arte che ha maggiormente insistito sul significato politico degli affreschi di Giorgione e Tiziano, collegandoli direttamente agli eventi storici del tempo, è stato Michelangelo Muraro. ${ }^{85}$ Gli anni 1506-1509, già del resto ampiamente analizzati nelle monografie di Cavalcaselle-Crowe sul Vecellio ${ }^{86} \mathrm{e}$ di Simonsfeld sul Fondaco, furono ricchi di colpi di scena, e ripercorrendo brevemente gli episodi fondamentali di questo periodo travagliato si possono stabilire i seguenti punti fermi confrontandoli con i dati della storia dell'edificio:

il 16 giugno 1506 l'imperatore Massimiliano propose al Senato un'alleanza contro il re di Francia chiedendo al contempo il permesso di far marciare le sue truppe attraverso il territorio veneziano; 87

il 29 luglio 1506 venne messo in opera il primo solaio del Fondaco, il che implica l'esistenza di un progetto definitivo già ben avviato in un momento in cui l'armonia fra le due parti non si era ancora incrinata; 88

tuttavia il Senato non venne incontro ai desideri dell'imperatore e tergiversò sino alla fine del 1506, quando papa Giulio II e Massimiliano strinsero un'alleanza contro Venezia accolta con visibile turbamento in città come documentato dai diari di Marin Sanudo; 89

il 9 febbraio 1507 venne infine dichiarata la guerra; 90

al 15 marzo 1507 risale il completamento del tetto del Fondaco, come riportato nei Diari di Sanudo, termine post quem per gli affreschi di Giorgione; ${ }^{91}$

il 17 dicembre 1507 il doge Loredan definì i mercanti tedeschi come "conterraneos nostros;",92

il 19 gennaio 1508 si assegnarono le camere ai mercanti tedeschi; ${ }^{93}$

nei primi mesi del conflitto iVeneziani registrarono così tante vittorie da costringere l'imperatore a un trattato di pace siglato il 6 giugno 1508 , un accordo, in seguito disatteso, della validità di tre anni; ${ }^{94}$

l'8 novembre la Signoria ordinò ai Provveditori al Sale di esaminare la causa intentata dal pittore, termine ante quem degli affreschi di Giorgione al Fondaco. ${ }^{95}$

Da questo résumé risulta evidente che i dipinti vennero eseguiti in un momento di grande fluidità politica in cui messaggi di aper- 


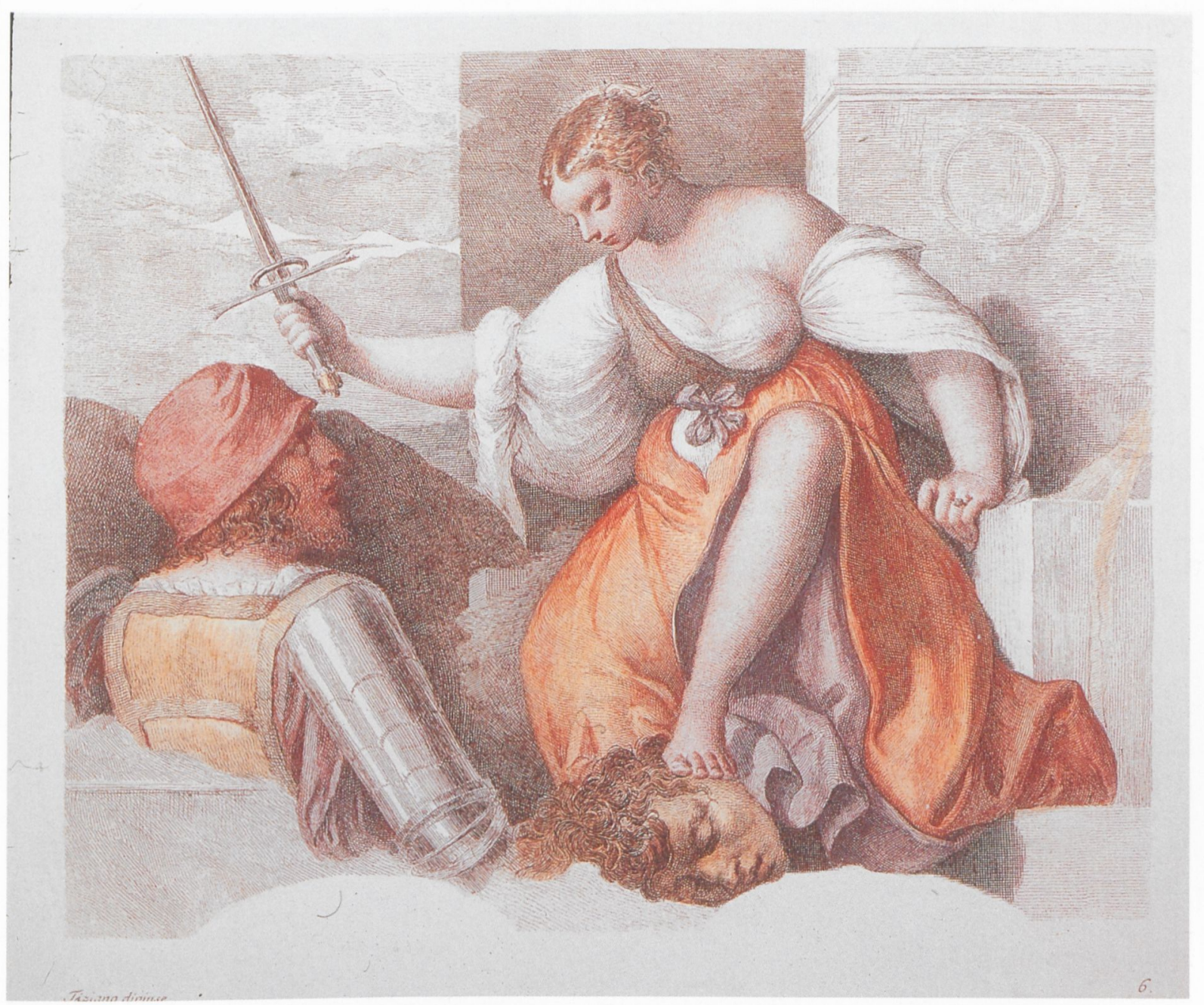

Fig. 12. Antonio Zanetti (da Tiziano), Giuditta/Giustizia incisione acquerellata. Roma, Bibliotheca Hertziana.

ta ostilità si alternavano a sforzi di rappacificazione. Né sembra corretto concentrarsi solo sui documenti di carattere apertamente politico e diplomatico trascurando la dimensione economica e sociale del fenomeno. I rapporti commerciali sono ridotti ma non vengono sempre rescissi in periodi di guerra e il doge non esitò a definire i mercanti tedeschi "conterraneos nostros" in un momento di alta tensione politica. Date queste circostanze ritengo improbabile che il ciclo del pittore di Castelfranco potesse rivestire la benché minima connotazione politica, in senso stretto. Sarebbe stata un'imprudenza inammissibile, mentre un tema neutrale con allusioni al mondo del commercio sormontato da due decisi ma pacifici leoni marciani non avrebbe creato problemi o malintesi.

Il caso della Giuditta di Tiziano, uno degli ultimi affreschi del Fondaco poiché si iniziava a dipingere una parete partendo dall'alto, è tuttavia diverso. Quasi ogni storico interessato alla questione è concorde nel datare l'esecuzione dei dipinti di Tiziano, non documentati, a un momento leggermente posteriore benché alcuni li ritengano assolutamente coevi; ${ }^{96}$ se Giorgione terminò la sua opera nell'estate o, al più tardi, all'inizio dell'autunno del 1508, è probabile che il Vecellio, le cui figure monumentali sembrano muovere una critica all'eleganza "ellenistica" degli affreschi del collega, sottintendendo così uno scarto stilistico di qualche mese, vennero realizzati, al più presto, nel tardo autunno dello stesso anno quando il clima politico degenerò. La Lega di Cambrai, sottoscritta dal papa, dall'imperatore, dal re di Francia e dalla Spagna oltre che dai signori di Ferrara, Mantova e Urbino, venne sancita solo il 10 dicembre 1508, dopo la conclusione del ciclo affrescato da Giorgione, ma l'inaudita tensione 
politica era già esplosa nelle settimane precedenti. Che durante un periodo così inquieto, culminato l'anno seguente nella disfatta di Agnadello del 14 maggio 1509, si potesse pensare di decorare l'ingresso al Fondaco con un'immagine ammonitrice come la Giuditta rientra nelle possibilità della storia. Soprattutto se si tiene presente che il "travestimento" biblico ne avrebbe in ogni caso smorzato l'attualità una volta calmatesi le acque.

Mi sembra tuttavia improbabile che la Giuditta possa essere interpretata esclusivamente come l'allegoria di un'aggressione politica, per quanto impostata alla difesa e non all'offesa. Una connotazione orientata decisamente in questa direzione avrebbe potuto risultare obsoleta qualche anno più tardi, come avvenne in effetti, e mi chiedo se non sia più saggio leggere la Giuditta-Giustizia in relazione con il leone di San Marco scolpito ai suoi piedi e accompagnato dalle parole PAX TIBI MARCE (fig. 10): il messaggio principale di questa parte della decorazione sarebbe pertanto quello della reciprocità fra pace e giustizia benché la sostituzione delle personificazioni con immagini alludenti a Venezia quale Repubblica pacifica (il motto inciso sulle pagine del libro marciano), giusta (la spada) e forte (non solo è il leone attributo della Fortezza, ma persino la figura di Giuditta poteva essere letta in questo senso ${ }^{97}$ ) carichi l'insieme di una connotazione senza dubbio ma non esclusivamente politica. In altri termini: la scena affrescata da Tiziano va messa in rapporto con gli elementi scultorei della facciata a illustrazione del versetto biblico justitia et pax osculatae sunt tratto dal Salmo 85 (84). Già il Wind, in un saggio su alcune opere del maestro di Castelfranco, ${ }^{98}$ aveva proposto di mettere in relazione fra loro i temi delle due facciate del Fondaco facendo ricorso al concetto di origine biblica e attribuendo l'ideazione del programma a Giorgione: secondo Wind l'artista avrebbe assegnato a Tiziano, da lui visto nella funzione di assistente, il Trionfo della Giustizia sulle Mercerie riservandosi il compito di affrescare il Trionfo della Pace. ${ }^{99}$ Questo tema iconografico sarebbe stato illustrato - secondo l'ipotesi di Wind — da un affresco allegorico perduto ma tramandato da un'incisione di Hendrick van der Borcht il Giovane. ${ }^{100}$ Ipotesi ingegnosa: senonché un disegno preparatorio per questa composizione spetta oltre ogni possibilità di dubbio al

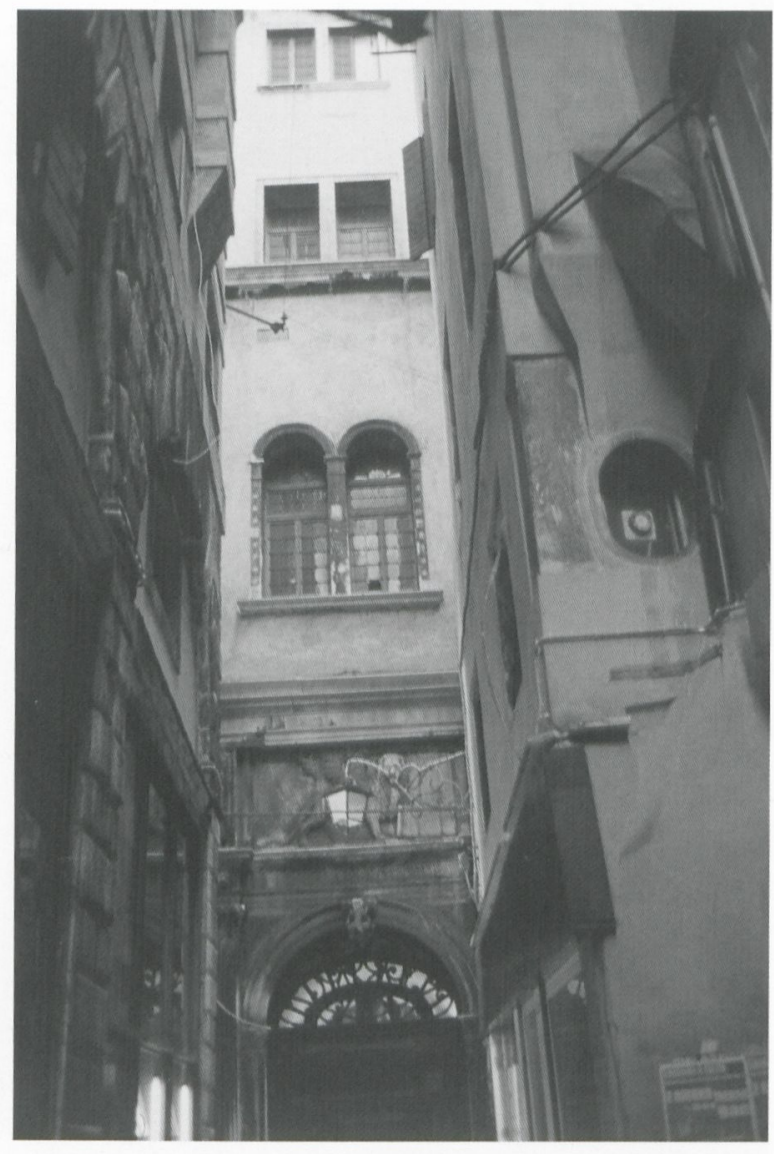

Fig. 13.Veduta dell'ingresso al Fondaco (Foto Nova).

Pordenone e l'affresco non aveva nulla a che vedere con il Fondaco. ${ }^{101}$ La tesi di Wind di un tema comune per ambedue le facciate del Fondaco è stata dunque smentita, ma ciò non vuol dire che si debbano scartare le sue considerazioni su uno dei possibili motivi iconografici della decorazione dell'edificio: a mio modo di vedere la figura palesemente aggressiva della Giuditta andava letta in rapporto con il placido ma fermo leone marciano scolpito sopra il portone d'ingresso. ${ }^{102}$

Inoltre le due figure muliebri un tempo probabilmente affrescate al di sopra della Giuditta e i cui frammenti sono per fortuna documentati dalle incisioni dello Zanetti andavano lette in una relazione iconografica con la figura sottostante $\mathrm{e}^{103}$ (figg. 13 e 14): se riteniamo plausibile che l'eroina biblica alludesse sia alla Fortezza che alla Giustizia oppure se proponiamo di associare la prima virtù cardinale con il leone araldico della Serenissima, le due donne avrebbero potuto rappresentare la Prudenza e la Temperanza. Esiste una tradizione aVenezia per decorare gli edifici pubblici con le virtù 


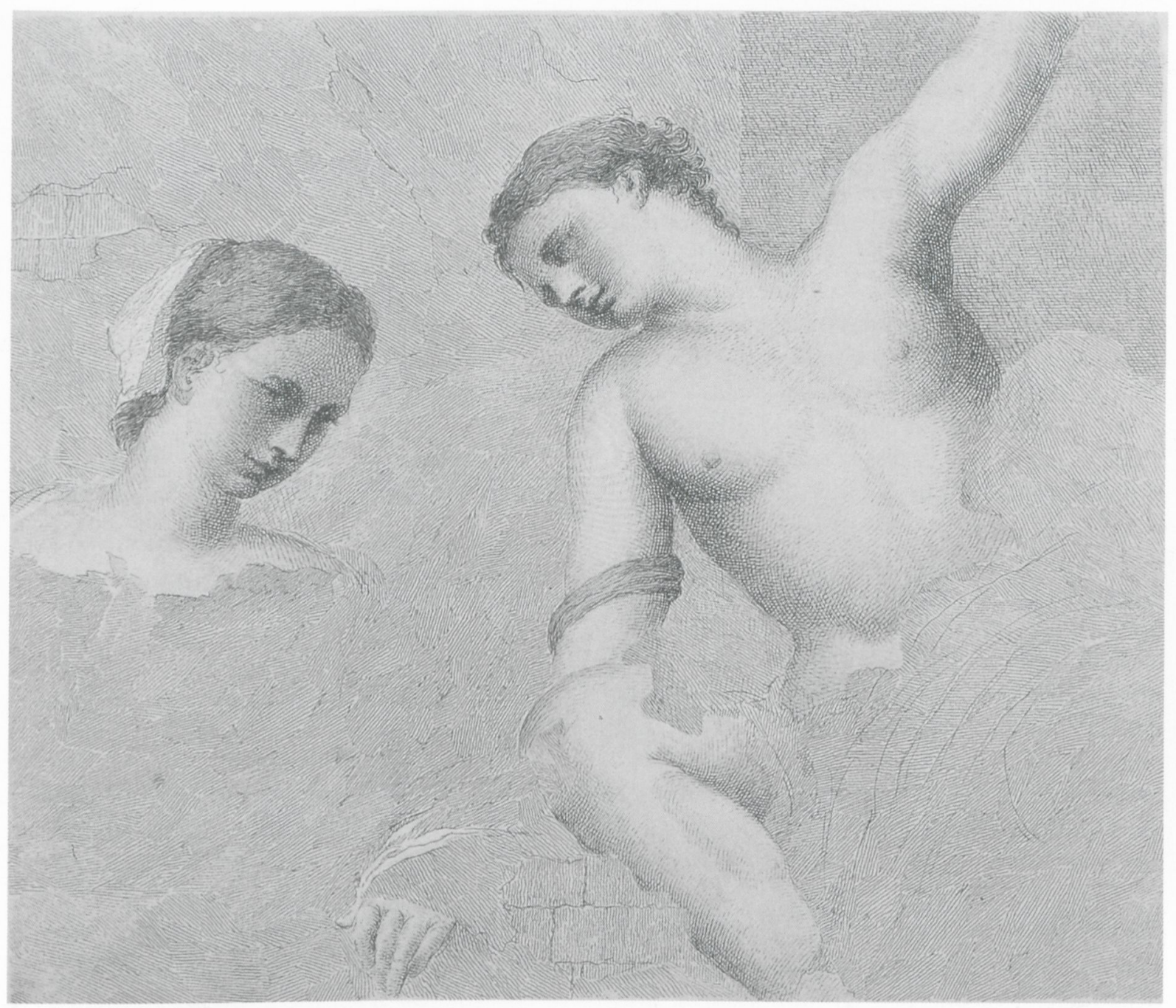

Fig. 14. Antonio Zanetti (da Tiziano), Due figure allegoriche, incisione acquerellata. Roma, Bibliotheca Hertziana.

- basti pensare all'ingresso cerimoniale al palazzo del doge, la Porta della Carta - né va dimenticato che il Filarete nel decimo libro del suo trattato riteneva opportuno decorare la porta del palazzo comunale sulla piazza del mercato con le quattro virtù cardinali. ${ }^{104}$ Questa parte al centro del prospetto meridionale del palazzo avrebbe dovuto essere letta pertanto in modo indipendente dal resto della facciata, anche se in origine la percezione dell'edificio non era ostacolata, come oggi, dalle alte case circostanti. Infatti, benché molte vedute cinquecentesche documentino come i caseggiati a ridosso del Fondaco non si erigessero al livello attuale, ${ }^{105}$ dimostrando così quanto il lato affrescato da Tiziano godesse un tempo di una visibilità maggiore di quella oggi immaginabile, ${ }^{106}$ resta pur tuttavia il fatto che la calle di accesso esistesse già prima dell'erezione dell'attuale strut- tura. Ciò è indicato non solo dalla pianta di Jacopo de' Barbari ma anche dal fatto che l'attuale porta d'ingresso non è allineata sul cortile bensì è posta in asse con la strada, come aveva già notato Giovanni Antonio Selva nella sua scheda a commento delle "fabbriche cospicue" del Cicognara all'inizio dell'Ottocento, ${ }^{107}$ prova sicura dell'esistenza di una via precedente allo sviluppo del quartiere sorto intorno al Fondaco odierno. In altre parole: il nuovo portale venne eretto esattamente nel luogo in cui si trovava nel palazzo precedente ed è quindi probabile che dopo l'incendio venissero riedificate anche le case ai lati della calle, quinte di una piramide visiva convergente verso l'ingresso che ne isolava la decorazione dal resto della facciata. Il leone marciano, la Giuditta e le altre due figure muliebri godevano pertanto di una posizione privi- 
legiata venendo osservate ogni giorno da chi entrava o rientrava nel Fondaco, ai loro piedi si svolgevano le processioni più opulente dei mercanti tedeschi che, partendo dalla vicina chiesa di San Bartolomeo dove era la loro cappella, terminavano nel cortile e avevano luogo nelle vigilie di Natale, dell'epifania e della festa della purificazione: a loro era dunque affidato il compito specifico di salutare e ammonire chi si avvicinava al centro dei commerci indipendentemente dagli altri motivi dipinti da Tiziano sulla facciata meridionale dell'edificio.

Per quanto concerne gli altri affreschi di Tiziano si devono prendere in considerazione le descrizioni storiche del Ridolfi, del Boschini e di Giovanni Bartolomeo Milesio nonché i numerosi lacerti oggi conservati alla Ca' d'Oro. È meglio partire dal Milesio perché fornisce qualche particolare iconografico ignorato dalle altre fonti. L'archivista del Fondaco scrisse intorno al 1715:" Terza Facciata, a Mezogiorno del Portone di Strada. [...] Si vede una Giuditta con la spada alla mano, e sotto i piedi il Capo reciso del principe Holoferne [...] et un soldato armato [...] collocate sopra il Portone. Nel cantonale verso il Ponte di Rialto vi è una Eva. [...] Sopra la detta facciata corre un Fregio a chiaroscuro, che cinge tutta la facciata con animali, Rabeschi ed altre varie fantasie. Nel muro della Torretta vi sono duo Uomini nudi, ne' quali si vede Pelle, Carne, Muscoli et attitudini [...] ma alquanto danneggiate dal Tempo. Nell'altro Cantone, verso la Calle della Bissa, vedesi una Venere Nuda, un Levantino, et un Cavalier di quelli Giovin Nobili Veneti antichi, detti della Calza, che costumavano portar una d'un color e l'altra dell'altro."108

Nessuno ha ricostruito questa parte della decorazione del Fondaco meglio di Paul Holberton nella sua dissertazione, ma poiché il suo testo è tuttora inedito ne presenterò qui solo una sintesi parziale. ${ }^{109}$ Oltre ai particolari decorativi tuttora conservati - trofei militari, uno stemma araldico, putti e tritoni, putti e animali fantastici - Tiziano dipinse sulla parete del piano superiore alcune figure nude monumentali tra cui laVenere nuda ricordata dal Milesio, mentre all'altezza del piano nobile, sul lato verso il Canal Grande, rappresentò un'altra nuda (identificata dal Milesio come Eva benché il Boschini l'avesse solo descritta come "una figura ignuda in piedi, che pare il ritratto di quella perfetta Donna, che creò Iddio di sua mano"110) di cui posse-

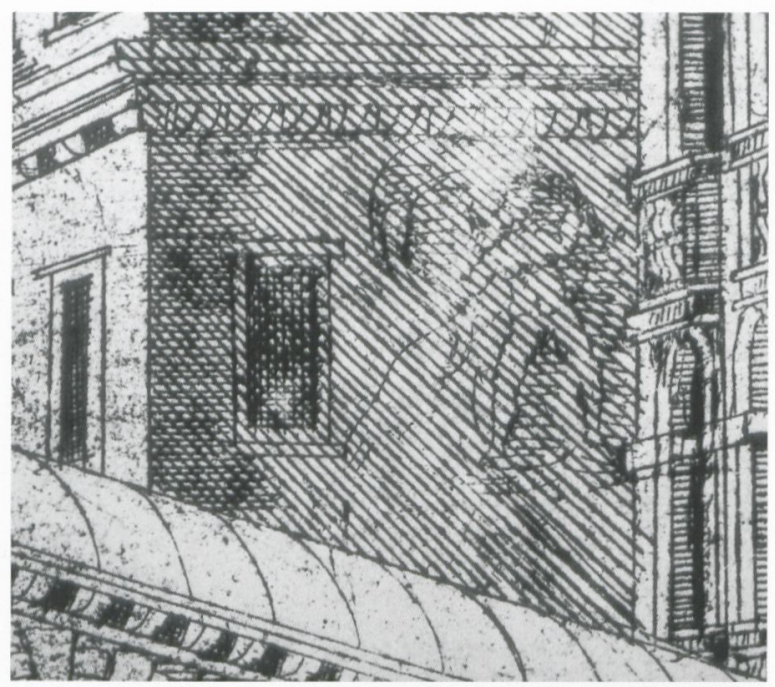

Fig. 15. Anonimo, Il Ponte di Rialto, particolare, incisione. Copenaghen, Statens Museum for Kunst.

diamo una testimonianza figurativa nell'incisione seicentesca di Jacopo Piccini, descritta dallo Zanetti come abbastanza veritiera, e in una tela a grandezza naturale attribuita a Pietro Liberi. ${ }^{111}$ Sul lato verso campo San Bartolomeo, sempre al piano nobile, erano invece affrescati quattro uomini abbigliati in modo vistoso sulla cui identità regna una certa confusione. Holberton ritiene che Tiziano abbia dipinto quattro figure virili simili, con calze bicolori e ampi mantelli, negli ultimi quattro spazi tra le finestre numero $17 \mathrm{e}$ numero 24. I due personaggi verso il portone d'ingresso sono da identificare nei lacerti oggi alla Ca' d'Oro; dei due personaggi verso la salizzada, uno ci è noto attraverso un'incisione dello Zanetti e l'altro è descritto in modo adeguato nella monografia di Crowe e Cavalcaselle dedicata a Tiziano. Secondo Holberton si trattava di un gruppo omogeneo di quattro bravi o solda$t i{ }^{112} \mathrm{Ma}$ è difficile intuire il loro rapporto iconografico con le figure ignude del piano superiore.

Solo di recente è stato inoltre possibile far luce su altri particolari della facciata meridionale, forse uno dei due uomini nudi tanto lodati dal Milesio. Già il Ridolfi aveva descritto ai livelli più alti del prospetto sulle Mercerie "un giovanetto ignudo in piedi, che stringe un drappo in guisa di vela, et un bamboccio lograto dal tempo; e nella cima fece un altro ignudo, che si appoggia à grande tabella, ove sono scritte alcune lettere, che mal s'intendono." ${ }^{113}$ Eppure solo la scoperta del primo stato incompiuto di un'incisione (fig. 15), noto 

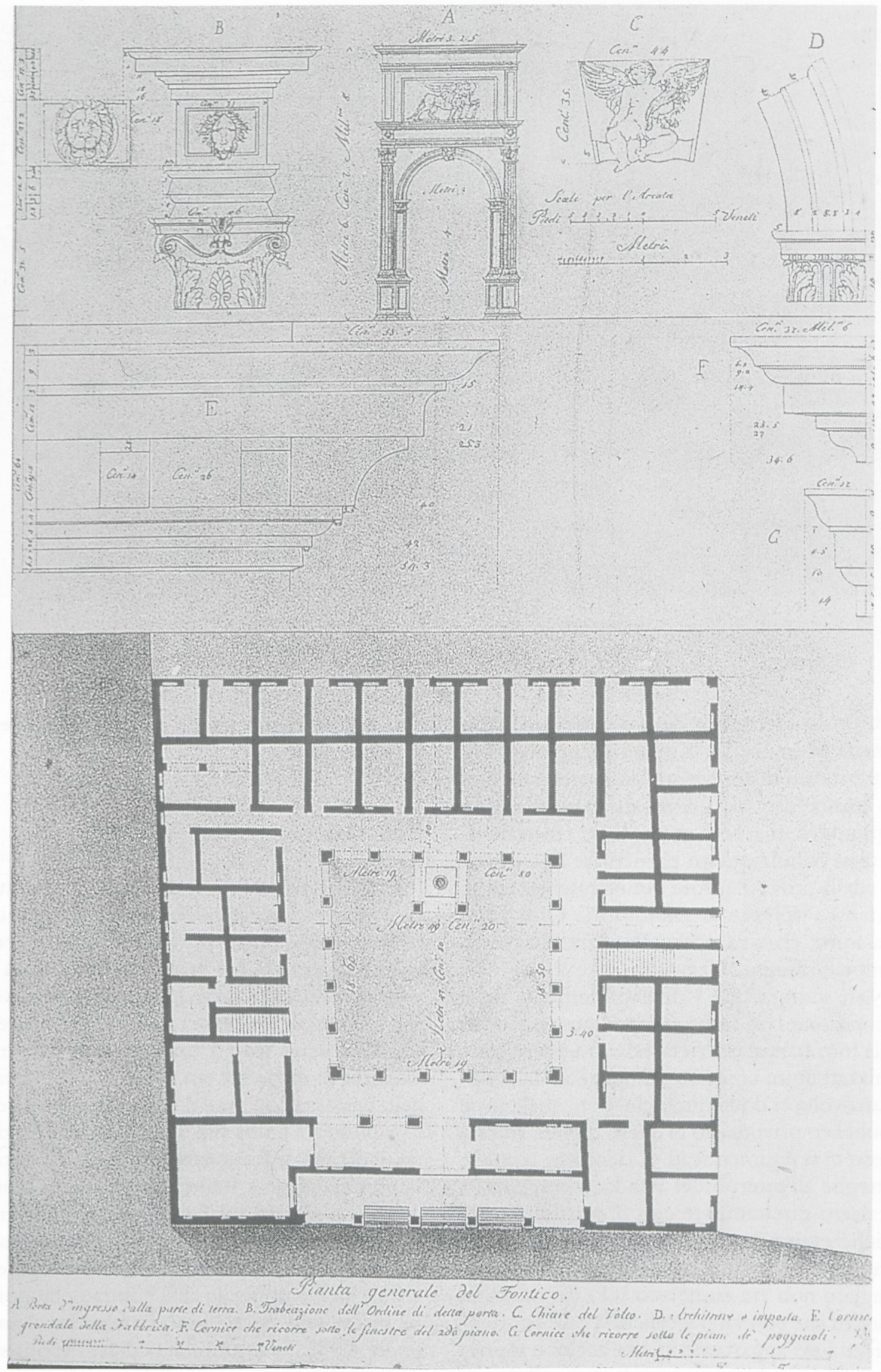

Fig. 16.Vincenzo Fadiga, pianta del Fondaco dei Tedeschi, in Cicognara, Le Fabbriche e i monumenti cospicui di Venezia, Venezia 1858, tavola 93. 


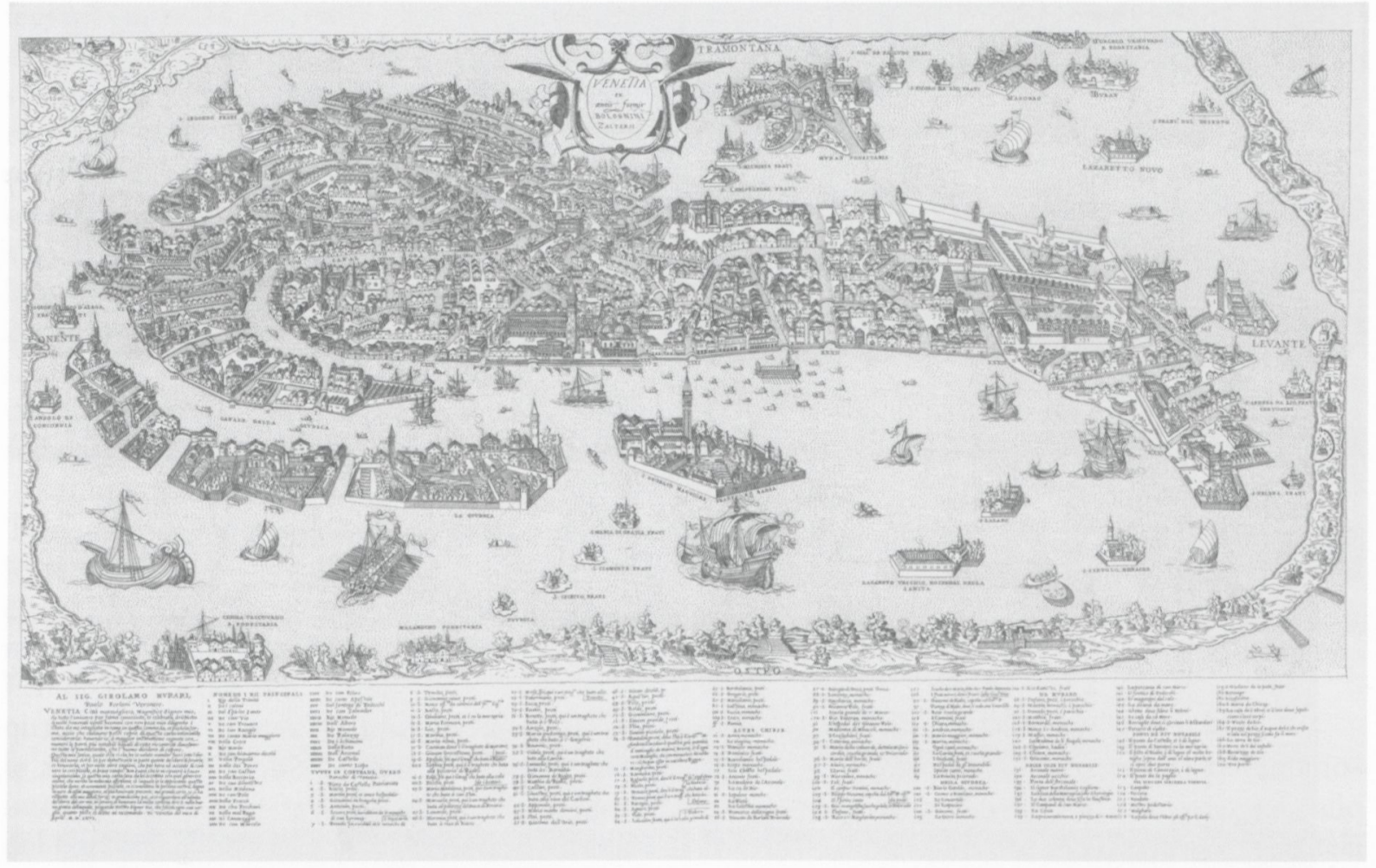

Fig. 17. Paolo Forlani, pianta di Venezia, 1566.

in un solo esemplare oggi conservato nello Statens Museum for Kunst in Copenaghen, ha permesso di formulare un'ipotesi sull'uomo muscoloso (non certo un fanciullo) che impugnava una vela: secondo le ricerche di Juergen Schulz questo particolare documentato dalla prova d'autore dimostrerebbe come Tiziano s'ispirasse ai Dioscuri del Quirinale, una fonte classica nota a Venezia attraverso stampe e disegni. ${ }^{114}$

Non sembra che i diversi elementi della decorazione, così come ci sono stati tramandati nella loro frammentarietà, possano essere riorganizzati in un contesto omogeneo. $\mathrm{Ma}$ ancora una volta ci dovremmo chiedere quale fosse il pubblico privilegiato di questi dipinti. Troppo spesso ci si è dimenticati di ricordare come le botteghe all'esterno del Fondaco non comunicassero direttamente con il cortile (fig. 16) poiché erano date in affitto a commercianti veneziani. ${ }^{115}$ In altri termini: il pubblico privilegiato non era composto solo dai mercanti tedeschi che potevano scegliere la calle per rientrare ai loro appartamenti, ma anche e soprattutto dai mercanti veneziani che in quella stretta via operavano quotidianamente. Difficile ricostruire il significato e la funzione degli affreschi per quel pubblico, ma da qui dovrà muoversi la ricerca futura.

\section{Conclusione}

Le questioni aperte sono molte. Spero tuttavia di aver indicato alcune linee di metodo: la supremazia, sino a prova contraria, del certo sull'ipotetico, ma anche la legittimità di vagliare con attenzione alcuni dati forniti da fonti visive all'apparenza non del tutto attendibili, almeno sino a quando non potremo disporre di elementi più solidi; ma il primato della certezza non vuol dire che lo storico debba rinunciare a una sua fondata immaginazione, al diritto di formulare ipotesi da confutare oppure correggere. Inoltre riusciremo a far progredire la ricerca sul Fondaco solo se saremo in grado di creare una banca dati elettronica in cui vengano raccolte tutte le fonti documentarie e visive non solo dell'edificio che qui ci ha interessato ma dell'intera zona intorno al ponte di Rialto. La possibilità di far riferimento una volta per tutte a un'edizione definitiva dei documenti storici e artistici, senza l'uggia della ripetizione necessariamente frammentaria 
dei dati, permetterebbe agli studiosi di concentrarsi sulle ipotesi più nuove dando per scontati i dati acquisiti. Un modello metodologico esiste già, la meravigliosa monografia di James Ackermann sul Cortile del Belvedere in Vaticano pubblicata esattamente cinquant'anni or sono: in quel volume si trovano tutti i documenti rilevanti a dirimere le fasi della crescita e della distruzione della struttura rinascimentale. I problemi della ricerca sul Fondaco sono invece in parte legati alla frammentazione delle competenze, ma non è possibile separare i problemi iconografici e stilistici dei dipinti del Fondaco dalla storia sociale del quartiere e del commercio internazionale, come spero di aver dimostrato in questa sede. 


\section{NOTES}

\begin{abstract}
${ }^{1}$ Vorrei ringraziare Sylvia Ferino-Pagden per l'amichevole invito al convegno. A Charles Hope va inoltre la mia più viva gratitudine non solo per aver messo a disposizione la filza del suo archivio privato con i documenti sul Fondaco dei Tedeschi da lui raccolti in prospettiva di una monumentale edizione delle fonti tizianesche, ma soprattutto per avermi segnalato il dipinto della Pinacoteca Comunale di Ascoli Piceno, sinora trascurato dagli studi sull'edificio. Stefano Papetti, consulente scientifico delle Collezioni Comunali di quella città, è stato di una cortesia squisita nel far fotografare in tempi rapidissimi la tela, il cui restauro si è concluso nel settembre 2004, e nell'inviare la relativa documentazione fotografica. Paul Holberton $\mathrm{mi}$ ha permesso di consultare le pagine dedicate alla decorazione del Fondaco nel suo Ph.D. del Warburg Institute che già da tempo avrebbe meritato di vedere la luce in forma monografica: P. Holberton, Poetry and Painting in the Time of Giorgione, Warburg Institute (London University) 1989, pp. 25-65. Matteo Burioni si è prodigato per facilitare ogni aspetto pratico della ricerca, ma ho anche tratto profitto dai nostri frequenti scambi di idee: a lui, come agli altri, va pertanto la mia più sincera riconoscenza.
\end{abstract}

${ }^{2}$ J.Anderson, Giorgione. Peintre de la "brièveté poétique», Parigi 1996. J.Anderson, Giorgione. The Painter of 'Poetic Brevity', New York 1997.

${ }^{3}$ S. Rossi, Fondaco dei Tedeschi, Nuda e Putto alato, in: a cura di G. Nepi Scirè e S. Rossi, Giorgione. "Le maraviglie dell'arte", Venezia 2003, pp. 150-161. La scheda è rielaborata e ridotta nella versione austriaca: S. Rossi, Nuda, in: S. Ferino-Pagden e G. Nepi Scirè, Giorgione. Mythos und Enigma,Vienna 2004, pp. 215-218. In ambedue i testi sono assenti due riferimenti bibliografici di peso: G. Schweikhart, Der Fondaco dei Tedeschi: Bau und Ausstattung im 16. Jahrhundert, in: B. Roeck, K. Bergdolt e A.J. Martin, Venedig und Oberdeutschland in der Renaissance. Beziehungen zwischen Kunst und Wirtschaft, Sigmaringen 1993, pp. 41-49; si veda inoltre J. Schulz, "Titian and the Fondaco dei Tedeschi”, in: The Burlington Magazine 143 (2001), pp. 567569.

${ }^{4}$ E. Concina, Fondaci. Architettura e mercatura tra Levante, Venezia e Alemagna, Venezia 1997, soprattutto il capitolo 4, Mercatura e Rinascimento a Venezia: dal "fontego novo" di San Marco alla "germanorum domus", pp. 145-217.

${ }^{5}$ G. Nepi Scirè, Giorgione. Nuda, in: Giorgione a Venezia, Milano 1978, pp. 117-129 e F.Valcanover, Tiziano Vecellio. "Giuditta" (La Giustizia), Combattimento di nomini e mostri, Tritone e putto, Combattimento di un putto con un mostro, Stemma, in: Giorgione a Venezia, Milano 1978, pp. 130-142.

${ }^{6}$ G.M.Thomas, Capitular des Deutschen Hauses in Venedig, Berlin 1874.

${ }^{7}$ H. Simonsfeld, Der Fondaco dei Tedeschi in Venedig und die deutsch-venetianischen Handelsbeziehungen, Stoccarda 1887, 2 volumi (ne esiste anche una versione ridotta, in un solo volume, indirizzata a un pubblico di amatori e priva dell'imponente apparato documentario).

${ }^{8} \mathrm{~T}$. Temanza, Vite dei più celebri architetti e scultori veneziani che fiorirono in Venezia nel secolo XVI,Venezia 1778, p. 90.

${ }^{9}$ L. Cicognara, A. Diedo e G.A. Selva, Le fabbriche e $i$ monumenti cospicui di Venezia, Edizione con copiose note ed aggiunte di Francesco Zanotto arricchite di nuove tavole e della versione francese, vol. I,Venezia 1858, p. 151:"Theutonicum mira- re forum spectabile fama / Nuper Iucundi nobile fratris opus." Non ho potuto consultare le prime due edizioni del 1815-20 e del 1838.

${ }^{10}$ Simonsfeld, 1887, pp. 113-115.

11 Oltre al suo intervento in Il Fondaco nostro dei Tedeschi, Venezia 1941, pp. 13-48, si veda soprattutto M. Dazzi, "Sull'architetto del Fondaco dei Tedeschi", in: Atti del Reale Istituto Veneto di Scienze, Lettere ed Arti, 99, Parte II, Anno accademico 1939-40, pp. 873-896. Anche Jacob Burckhardt riteneva che questo semplice edificio di grandi proporzioni fosse stato progettato da Fra Giocondo nel 1506: si veda J. Burckhardt, Der Cicerone. Eine Anleitung zum Genuss der Kunstwerke Italiens (1855), in: Jacob Burckhardt Werke. Kritische Gesamtausgabe, a cura di B. Roeck, Ch. Tauber e M. Warnke, vol. 2, Monaco di Baviera e Basilea, 2001, pp. 184 (221) e 242 (296).

${ }^{12}$ M.Tafuri, Venezia e il Rinascimento, Torino 1985, pp. 46 e $57-59$.

${ }^{13}$ Per la delibera del 28 maggio 1506 e le lamentele di Fra Giocondo si veda Dazzi, 1939-40,pp. 880 e 882. Per la posa in opera del primo solaio, il 29 luglio 1506, si veda Simonsfeld 1887, vol. 1, p. 353, n. 641.

14 Oltre al panegirico citato nel testo, Dazzi, 1939-40, p. 873 , nota 1 , ricorda altri due manoscritti del Contarini in cui l'autore attribuisce il Fondaco a Fra Giocondo. Nell' Argo vulgar stampato a Venezia da Alvise de Tortis, a quanto pare nel 1538, si legge: "Da poi passemo el ponte che fa do parte de la città e prima admiremo el fontego dove habitano li ricchi todeschi fatto in tre soleri, i muri sum marmorei, lalteza de li quali va sopra le nube e gloria de Iucundo geometra." Nell'Argoa voluptas, la versione latina pubblicata a Venezia dal vercellese Bernardino de Vianis con privilegio datato 13 settembre 1541, si legge in versi:

"In geminas pontem partes qui dividit urbem transimus: primo sed lumina nostra moratur quae tegit ingentes opibus domus ardua Rhenos: marmoreis nubes superat nam machina muris: Gloria Iucundi geometrae."

15 Concina, 1997, p. 178.

${ }^{16}$ P. Selvatico, Sulla architettura e sulla scultura in Venezia dal Medioevo sino ai nostri giorni, Venezia 1847, p. 168.

17 Cicognara, Diedo e Selva, 1858, p. 153, nota 6.

${ }^{18}$ Sull'incarico allo Scarpagnino, che il 13 ottobre 1505 si vide riconosciuto un salario di cinquanta ducati l'anno a partire dal 16 agosto precedente, un dato a favore di un suo coinvolgimento assai precoce nei lavori del Fondaco, si veda P. Paoletti, L'architettura e la scultura del Rinascimento in Venezia, Venezia 1893 , p. 261 , nota 8 . Si tratta della prima opera documentata dello Scarpagnino a Venezia.

${ }^{19}$ Sulla data di morte dello Spavento ricordata dal Sanudo si veda Concina, 1997, p. 170.

${ }^{20}$ D. Romanelli, Il Fondaco dei Tedeschi, in: a cura di B. Aikema e B.L. Brown, Il Rinascimento a Venezia e la pittura del Nord ai tempi di Bellini, Dürer, Tiziano, Cinisello Balsamo 1999, p. 77.

${ }^{21}$ Tutti i dati e i fatti riportati nel testo sono tratti dai Diarii di Marin Sanudo o dai documenti archivistici raccolti dal 
Simonsfeld nel suo volume del 1887, spesso ripetuti nella letteratura sul Fondaco.

22 A detta del Sanudo, "[10 giugno 1505] fu posto et visto im pregadi li modelli dil fontego di todeschi [...] et che, esaminato il collegio ben li modelli di Spavento e dil todesco, poi si vegni a pregadi": si vedano I Diarii di Marin Sanuto, vol.VI, a cura di G. Berchet,Venezia 1881, col. 180.

${ }^{23}$ Venezia, Archivio di Stato, Pregadi, vol. 15, 19 giugno 1505. Oltre all'aggiunta del corsivo, ho modernizzato qualche accento e migliorato l'interpunzione per una lettura più spedita del testo. Il lungo passo è trascritto anche dal Dazzi, 193940 , p. 885.

${ }^{24}$ I Diarii di Marin Sanuto, 1881, vol.VI, col. 187.

${ }^{25}$ Almeno dai tempi di Crowe e Cavalcaselle circola la notizia della rimozione dall'incarico del cittadino tedesco da parte del nuovo responsabile della ricostruzione del Fondaco, Alvise Emo entrato in carica il 20 giugno 1505. L'Emo avrebbe allontanato senza alcun motivo apparente Hieronymus al quale sarebbe stato conferito un posto "nell'artiglieria a Cattaro": G.B. Cavalcaselle e J.A. Crowe, Tiziano. La sua vita e $i$ suoi tempi (1877-78), Firenze 1974, vol. 1, p. 68. L'opinione viene accolta anche nelle pubblicazioni più recenti benché Simonsfeld, 1887, pp. 114-115, ne avesse per tempo contestata l'autenticità.

${ }^{26}$ L. Puppi, Fondaco dei Tedeschi, in: a cura di R. Maschio, I tempi di Giorgione, Roma 1994, p. 53.

${ }^{27} \mathrm{~J}$. McAndrew, Venetian Architecture of the Early Renaissance, Cambridge (Mass.) e Londra 1980, pp. 426-455.

${ }^{28}$ Dazzi, 1939-40, p. 890: "Si può dire che a questo punto l'architetto del fondaco è il Pregadi e che la contaminazione del progetto è evidente." Per la citazione nel testo si veda la p. 896 , tenendo conto che venne scritta durante le prime battute della seconda guerra mondiale: "E tuttavia vorremmo considerare il fondaco come opera in qualche modo di collaborazione in cui l'ordinata distribuzione tedesca si sposa mirabilmente alle chiare forme architettoniche del rinascimento italiano."

$$
\begin{aligned}
& { }^{29} \text { Tafuri, 1985, p. } 59 . \\
& { }^{30} \text { Concina, 1997, pp. } 175-176 . \\
& { }^{31} \text { L. Foscari, Affreschi esterni a Venezia, Milano } 1936 .
\end{aligned}
$$

${ }^{32}$ Su queste ricerche si veda F.Valcanover, Venezia, in: Pittura murale esterna nel Veneto. Venezia e Provincia, Bassano 1991, p. 28.

33 Anche Concina, 1997, pp. 199-200, cerca di trovare un possibile antecedente fuori di Venezia, in particolare negli affreschi di Bramante e della sua scuola sulla facciata del Palazzo del Podestà a Bergamo che si ritiene eseguiti nel 1477 su commissione di Sebastiano Badoer.

${ }^{34}$ F. Sansovino, Venetia città nobilissima, Venezia 1581, pp. 134v-135r: "Scrive Pietro Guilombardo che visse l'anno 1330 in certi suoi memoriali, che il palazzo del comune in Rialto, era presso alla Beccaria, dove soleva esser la merceria, et che fu cominciato del 1332 et finito del 1324 et che fu dipinto per tutto, et che nel mese di Gennaio, vide scoprir le dette pitture." Secondo Bruno Nogara, nella scheda dedicata a questi cicli in Pittura esterna nel Veneto. Venezia e Provincia, Bassano 1991, p. 60 , n. 152, questo palazzo in seguito completamente distrutto dall'incendio dell'isola di Rialto nel 1513 era affrescato anche all'esterno: la sua fonte è lo stesso Sansovino, ma il poligrafo del Cinquecento dice solo che il palazzo, da lui mai visto di persona perché nacque a Roma nel 1521, "fu dipinto per tutto" senza accennare a decorazioni esterne.

35 Sempre a Rialto esisteva una Loggia affrescata con $\mathrm{La}$ battaglia del Canal Orfano e la rotta di Pipino a cui faceva riscontro un Mappamondo. Sembra che gli affreschi risalissero al tre- dicesimo secolo, ma vennero ridipinti quando la loggia venne ricostruita nel 1459. Scomparsa nell'incendio devastante del 1513, al suo posto sorse l'attuale Palazzo dei Camerlenghi. Per un compendio di queste notizie e delle relative fonti si veda la scheda di Bruno Nogara in Pittura esterna nel Veneto. Venezia e Provincia, Bassano 1991, p. 60, n. 151.

36 Pittura esterna nel Veneto. Venezia e Provincia, Bassano 1991, p. 64, n. 166 (scheda a cura di Bruno Nogara).

${ }^{37}$ Sulla giovane età di Tiziano si veda la testimonianza credibile del Dolce: L. Dolce, Dialogo della Pittura intitolato l'Aretino, Venezia 1557, in: P. Barocchi, Trattati d'arte del Cinquecento, vol. 1, Bari 1960-62, pp. 163-164:"'questa illustrissima Signoria [...] fece ancora $[\ldots]$ dipingere dal di fuori il fondaco de'Tedeschi a Giorgio da Castelfranco, et a Tiziano medesimo, che alora era giovanetto." La prima fonte a stampa a ricordare gli affreschi del Fondaco è il Da pintura antiga di Francisco d'Olanda, uscito il 18 febbraio 1548. Si veda Francisco d'Olanda, I trattati d'arte, a cura di G. Modroni, Livorno 2003, p. 117:"Poi a Venezia ci sono splendide opere del cavalier Tiziano, uomo valente in pittura e nel ritrarre: tra queste, quelle nella Libreria di San Marco, e quelle nel Fondaco dei Tedeschi, e nelle chiese altre opere di altre buone mani. E tutta quella città è una buona pittura."

${ }^{38}$ Nella seconda edizione delle Vite il Vasari ricorda, illustrando la biografia di Tiziano, che il pittore ottenne l'allogazione degli affreschi sulla Merceria grazie all'intercessione di un membro della famiglia Barbarigo. Concina, 1997, pp. 184185 , ritiene la notizia plausibile.

${ }^{39}$ Qui mi limito a fornire qualche citazione tratta da alcune pubblicazioni specifiche per documentare lo stato della questione.

Foscari, 1936, pp. 23 e 125: Da un lato ricorda come l'inizio della tipologia sia fatto risalire a Giorgione benché il dipinto di Gentile Bellini con il Miracolo al ponte di San Lorenzo ne documenti l'esistenza già alla fine del Quattrocento, ma poi conclude il volume con queste parole: "La storia delle decorazioni a fresco esterne a Venezia si limita, prescindendo da quelle a motivi ornamentali degli edifici archiacuti, a un solo secolo, il Cinquecento, e si risolve con esso."

S. Romano, La facciata di Palazzo Trevisan a Murano, in: Urbs picta. La città affrescata nel Veneto (Omaggio a Luigi Coletti), Atti del Convegno di Studi (Treviso 10-12 giugno 1982), Treviso 1986, p. 95: L'aspetto vivace e colorato che la città di Venezia doveva avere già in epoca gotica è provato, oltre che da qualche testimonianza figurativa, dai numerosi lacerti che ancora sono visibili sulle facciate delle case veneziane. Si tratta però di decorazioni "realizzate con intento principalmente decorativo $[\ldots]$ in un ambito sì di grande vivacità realizzativa, ma sostanzialmente artigianale, opera di botteghe specializzate che lavorano a stampo o a spolvero. [...] Con l'avvicinarsi della fine del “400, il fenomeno muta confini e si estende," benché nessun ciclo si sia salvato dei tanti ricordati dalle fonti."Eppure, le facciate dipinte, già dai primissimi del ' 500 , divengono un campo ambito in cui i grandi artisti rivaleggiano fra loro."

F. D'Arcais, Le facciate dipinte nel Veneto, in: a cura di E. Castelnuovo, Luochi della luna. Le facciate affrescate a Trento, Trento 1988, pp. 33 e 39:"L'uso di ornare di affreschi le facciate degli edifici, chiese, palazzi pubblici e privati è nel Veneto antichissimo. [...] Ma si fa risalire a Giorgione l'introduzione a Venezia delle composizioni con figure a decorare esternamente gli edifici." Nella nota 10 a pagine 45 l'autrice corregge tuttavia il tiro: "In realtà le facciate dipinte esistevano in Venezia già prima" come dimostra il celebre dipinto di Gentile Bellini.

Valcanover, 1991, pp. 29-30 ritiene che le pitture delle facciate si siano diffuse a partire dal Duecento mano a mano che l'edilizia in pietra e mattoni sostituiva quella in legno. Col tempo si affermarono anche le decorazioni figurate come testi- 
moniano i dipinti del Mansueti e di Gentile Bellini, ma l'epoca più felice di questa tipologia resterebbe il Cinquecento.

In altre parole, quasi tutti gli autori si appellano all'autorità del dipinto belliniano e a pochi altri stralci documentari, ma alla fine sembra sempre prevalere il sentimento di una svolta radicale avvenuta con gli affreschi del Fondaco.

${ }^{40}$ Sul ruolo svolto da Cosimo Bartoli nella stesura della biografia dei due pittori veneti nella seconda edizione delle Vite si veda il contributo di Charles Hope in questo volume.

${ }^{41}$ Burckhardt (1855), vol. 2, 2001, pp. 241-242 (295-296).

${ }^{42}$ Burckhardt (1855), vol. 2, 2001, p. 239 (292), nota 1.

${ }^{43}$ G.Vasari, Le vite de' più eccellenti pittori, scultori ed architettori (1568), edizione a cura di G. Milanesi, vol. 6, Firenze 1906, p. 230.

${ }^{44}$ Vasari (1568), 1906, pp. 231-233.

${ }^{45}$ G.P. Lomazzo, Trattato dell'arte della pittura, libro VI, capitolo XXVIII, in: G.P. Lomazzo, Scritti sulle Arti, a cura di R.P. Ciardi, vol. 2, Firenze 1974, pp. 305-306.

46 Cito da Die Anfänge der Maniera Moderna. Giorgio Vasaris Viten. Proemio, Leonardo, Giorgione, Correggio, Übersetzung und Bearbeitung von S. Feser und V. Lorini. Wissenschaftliche Leitung: A. Nova, Hildesheim - Zürich - New York 2001, p. 117.

${ }^{47}$ E. Cozzi, Programmi iconografici sulle facciate dipinte a Trento fra Quattro e Cinquecento, in: a cura di E. Castelnuovo, Luochi della luna. Le facciate affrescate a Trento, Trento 1988, pp. 244-248, in particolare la p. 247.

48 Per questo dato si veda M. Bellabarba, Figure di nobiltà a Trento nei primi decenni del XVI secolo, in: a cura di E. Castelnuovo, Luochi della luna. Le facciate affrescate a Trento, Trento 1988, p. 48.

${ }^{49}$ Innumerevoli esempi sono documentati al nord delle Alpi. Si vedano a questo proposito M. Baur-Heinhold, Bemalte Fassaden. Geschichte, Vorbild, Technik, Erneuerung, Monaco di Baviera 1975; la voce Fassadenmalerei di Ch. Klemm nel Reallexikon zur deutschen Kunstgeschichte, vol. 7, Monaco di Baviera 1981, coll. 690-742; e S. Tipton, Res.Pvblica. Bene. Ordinata. Regentenspiegel und Bilder vom guten Regiment, Rathausdekorationen in der Frühen Neuzeit, Hildesheim - Zürich - New York 1996.

A Venezia è ben noto l'episodio straordinario della facciata del palazzo di Lodovico Talenti sul Canal Grande, in seguito di proprietà del mercante di origine fiamminga Martino d'Anna, affrescata dal Pordenone entro il settembre 1538. Non mi sembra che sia mai stata notata nella letteratura l'ironia tipicamente manieristica con cui il Pordenone trattò il tema: secondo Tito Livio ( $A b$ urbe condita, VII, 6, 1-7) ed altre fonti (ad esempio Valerio Massimo, Factorum et dictorum memorabilium libri novem, $\mathrm{V}, 6,2)$ Marco Curzio si sarebbe sacrificato per la patria gettandosi in una voragine da cui scaturivano fuoco e fiamme. Il cavaliere al galoppo del Pordenone si getta invece nelle acque del Canal Grande. Ma si veda ora l'analoga osservazione in B. De Maria, "The patron for Pordenone's frescoes on Palazzo Talenti d'Anna,Venice”, in: The Burlington Magazine 146 (2004), pp. 548-549.

${ }^{50}$ N. Machiavelli, Legazioni e commissarie, a cura di S. Bertelli, vol. 2, Milano 1964, p. 1085.

${ }^{51}$ Si veda Cozzi, 1988, p. 246.

${ }^{52}$ H. Lutz, Augsburg und seine politische Umwelt 1490-1555, in: a cura di G. Gottlieb e altri, Geschichte der Stadt Augsburg von der Römerzeit bis zur Gegenwart, Stoccarda 1984, pp. 413-433, in particolare p. 415 .

53 E. Castelnuovo, I luochi della Luna, in: a cura di E. Castelnuovo, Luochi della luna. Le facciate affrescate a Trento,
Trento 1988, p. 20. Su Peutinger si veda H. Lutz, Conrad Peutinger. Beiträge zu einer politischen Biographie, Augusta 1959.

${ }^{54}$ B. Bushart, Kunst und Stadtbild, in: a cura di G. Gottlieb e altri, Geschichte der Stadt Augsburg von der Römerzeit bis zur Gegenwart, Stoccarda 1984, pp. 363-385, la citazione è a p. 364.

${ }^{55} \mathrm{Si}$ veda su questo tema soprattutto Castelnuovo, 1988 , pp. 19-22.

${ }^{56}$ Per gli affreschi di Nicola Giolfino eseguiti, a quanto pare, intorno al 1542 si vedano: G. Schweikhart, Fassadenmalerei in Verona von 14. bis zum 20. Jahrhundert, Monaco di Baviera 1973, pp. 224-226; M. Repetto, Gli affreschi di Nicola Giolfino, in: a cura di P. Brugnoli, Tre case affrescate a Verona: vicende edilizie, decorazione pittorica e restauri, Verona 1990, pp. 27-44.

${ }^{57}$ P. Nanin, Disegni di varie dipinture a fresco in Verona, Verona 1864, tavole 35-36.

58 C. Ridolfi, Le maraviglie dell'arte overo le vite de gl'illustri pittori veneti e dello Stato (Venezia 1648), edizione a cura di D. von Hadeln, vol. 1, Berlino 1914, p. 100.

${ }^{59}$ A.M. Zanetti, Della pittura veneziana e delle opere pubbliche de' veneziani maestri,Venezia 1771, p. 93.

${ }^{60}$ Nepi Scirè, 1978, p. 123.

${ }^{61}$ Si veda fra gli altri: A. Gentili, Giorgio (Zorzi, Zorzo) da Castelfranco, detto Giorgione, in: Dizionario biografico degli italiani, vol. 55, Roma 2000, p. 359:"si trattava con ogni probabilità di un programma di contenuto astrologico"; interessante l'osservazione di Sandra Rossi nell'edizione italiana del catalogo della recente mostra giorgionesca secondo cui la Nuda potrebbe rappresentare Urania, la musa dell'astronomia (Rossi, 2003, p. 156). Si noti inoltre come l'altra figura muliebre incisa dallo Zanetti, che secondo la Rossi era collocata all'altezza del piano nobile insieme al personaggio virile riprodotto nel volume dello stesso autore, appoggi i suoi piedi su un oggetto sferico: Rossi, 2003, pp. 155 e 156.

${ }^{62}$ Sansovino, 1581, p. 133verso, definì l'isola di Rialto come "la prima piazza d'Europa."

${ }^{63}$ L'analisi seguente si basa sui risultati della monografia molto circostanziata di D. Calabi e P. Morachiello, Rialto: le fabbriche e il Ponte 1514-1591, Torino 1987.

${ }^{64}$ Per le magistrature si veda Calabi e Morachiello, 1987, pp. 27-28. I documenti relativi agli affreschi di Giorgione, già noti da tempo, sono integralmente trascritti in R. Maschio, Per la biografia di Giorgione, in: a cura di R. Maschio, I tempi di Giorgione, Roma 1994, pp. 178-203, in particolare le note a pagina 198 e le schede a pp. 202-203.

${ }^{65}$ Simonsfeld, 1887, p. 111, nota 2.

${ }^{66}$ La commissione istituita da Giovanni Bellini — il cui ruolo di sensale presso il Fondaco dovrebbe forse essere preso in maggiore considerazione in questa storia - per valutare l'operato di Giorgione era composta da Carpaccio, Mansueti e Vittore Belliniano, tutti pittori di Venezia senza esperienza nel campo delle facciate dipinte: il documento, citato molto spesso, è trascritto in Maschio, 1994, p. 198, nota 61. La riduzione del compenso di Giorgione da centocinquanta a centotrenta ducati aveva forse a che vedere con differenze insorte fra l'artista e Alvise Sanudo nella sua funzione di Provveditore al Sale responsabile per il Fondaco.

Chiunque sia stato realmente responsabile dell'allogazione degli affreschi sulla parete verso il Canal Grande, non va dimenticato che i pittori di facciate erano spesso scelti dai capomastri e che Giorgio Spavento, nella sua funzione di proto di San Marco, era a contatto con Giorgione anche per l'esecuzione del dipinto per la sala delle udienze in Palazzo Ducale. La notizia sul ruolo svolto dai capomastri come intermediari la si ricava dalla vita dello Schiavone del Ridolfi, 1914 (1648), vol. 1, p. 248: "Ne' suoi principij si diede Andrea à fatigar co' Dipintori, 
che facevano opere d'ogni qualità nelle botteghe; contrasse ancora amicitia co' Muratori, per haver occasione d'alcun lavoro, accostumandosi all'hora il dipingere gli aspetti delle case; onde veniva spesso data à Maestri detti la cura ancora della Pittura; si che lo havere il Muratore amico, cagionava la fortuna del Pittore." Anche Sebastiano Serlio si augurava nel suo trattato che tutti i collaboratori a un'impresa edilizia fossero rigidamente subordinati all'architetto, definito "padrone dell'opera", ma le sue parole fanno sorgere il dubbio che ciò in pratica non accadesse: si veda S. Serlio, I 7 libri dell'architettura, Venezia 1584 (ristampa anastatica, Bologna 1987), libro IV (1537), capitolo XI, p. 191v.

${ }^{67}$ Per queste magistrature vedasi Calabi e Morachiello, 1987, pp. 33-34.

${ }^{68}$ La tela con il numero di inventario 180 (catalogo 765$)$ è tradizionalmente ma senza fondamento attribuita al Bellotto. Il restauro è terminato nella tarda estate del 2004, come comunica Stefano Papetti, consulente scientifico della Pinacoteca.

${ }^{69}$ Nepi Scirè, 1978, p. 123.

${ }^{70}$ La relazione stesa da Guido Gerbino al termine dei restauri del 1939 denunciò la scadente qualità dei materiali impiegati nella costruzione del Fondaco (mattoni cotti insufficientemente e ottenuti da argille non all'altezza, pessima qualità di sabbia marnosa non lavata per confezionare le malte) e che sarebbero stati responsabili del degrado dell'edificio: si veda G. Gerbino, Relazione tecnica sui lavori di restauro e sistemazione, in: Il Fondaco nostro dei Tedeschi,Venezia 1941, p. 117.

${ }^{71} \mathrm{Si}$ noti tuttavia che nel dipinto gli spazi fra le finestre sono dieci, mentre nell'incisione e sulla facciata che vediamo oggi sono nove. A prima vista la tela sembra possedere una validità documentaria superiore ma non possiamo esserne certi.

${ }^{72}$ Si veda tuttavia K.-H. Ludwig, Metalle, Metallbearbeitung, in: Lexikon des Mittelalters, vol. 6, Monaco di Baviera e Zurigo 1993, coll. 568-569, che collega il piombo con Giove, il rame con Saturno e lo stagno con Venere.

${ }^{73} \mathrm{G}$. Luzzatto, Storia economica dell' età moderna e contemporanea, quarta edizione riveduta, Padova 1955, pp. 148-149.

${ }^{74}$ In uno degli edifici ai piedi del ponte lavoravano anche gli Ufficiali "alla tocca dell'argento" incaricati di marchiare i metalli lavorati: si veda Calabi e Morachiello, 1987, p. 27.

${ }^{75}$ Per un bel dettaglio del dipinto si veda Anderson, 1996, p. 276, a cui si deve l'utilizzo di questo documento visivo anche se non ne ha messo a frutto le informazioni, forse perché ignorava l'iscrizione riportata dal Cicogna.

${ }^{76}$ E.A. Cicogna, Corpus delle iscrizioni di Venezia e delle isole della laguna veneta, vol. 3, Venezia 2001, p. 1884.

${ }^{77}$ Vasari (1568), 2001, p. 118: ,V’è bene sopra la porta principale che riesce in Merzeria una femina a sedere." Sansovino, 1581, p.135v: "Le faccie da tutte le parti sono dipinte da primi huomini d'Italia. Conciosia che in quella dinanzi sopra la Merceria lavorò Titiano con sua grandissima lode."

${ }^{78}$ Il leone che vediamo oggi è la copia ottocentesca di un originale perduto.

${ }^{79}$ Ridolfi (1648), 1914, vol. 1, p. 100. È probabile che i trofei ricordati dalla fonte fossero simili a quelli affrescati da Tiziano sul lato delle Mercerie e a quelli illustrati nel Miracolo della croce a ponte San Lorenzo di Gentile Bellini. Le teste a chiaroscuro potrebbero riferirsi ai medaglioni all'antica o di imperatori diffusi nel Quattrocento che avrebbero potuto essere letti come un discreto omaggio a Massimiliano anche in un momento di turbolenza politica in cui gesti di riconciliazione si alternavano a quelli di aperta ostilità.

${ }^{80}$ Questa fonte fondamentale va riportata quasi nella sua completezza. Si veda G.B. Milesio, Fabbrica del Palazzo del Fontico de'Tedeschi (circa 1715), pubblicato da G.M.Thomas, "Giovanni
Battista Milesios Beschreibung des deutschen Hauses in Venedig”, in: Abhandlungen der Königlich Bayerischen Akademie der Wissenschaften, I.Cl., XVI, II Abtlg., 1881, p. 43: "Prescielti pertanto Giorgione e Tiziano; al primo toccò di dipingere la facciata sopra il Canal Grande, che mira il Ponente e l'altra sopra il Rio detto del Fontico situata verso Tramontana (così volle il Doge Loredano, di cui esso Giorgione fatto aveva il Ritratto di sua Serenità).A Tiziano quella del Portone di Strada che guarda il mezogiorno e l'altra della parte di Levante sopra la Strada, che conduce al ponte sudetto dall'oglio.

Prima facciata di Levante. In questa non vi sono quei graziosi comparti come nell'altra, à Mezogiorno, per la molteplicità delle finestre, e ferriate, che vi sono in ogni appartamento di essa.

Seconda Facciata a Ponente sopra il Canal Grande. Quanto di maestoso e vago può far l'Architectura civile, tanto fu dimostrato con le due lontananze di Colonnati Corintej, davanti le due Sale del primo appartamento, e nel mezo di detta Facciata dall'insigne Pennello di Giorgione da Castel Franco con ripartite e proporzionate vaghe figure colorate, a nicchi proprij col solito suo ardito Ingegno, natural decoro, et eccellente maestria nell'arte $[\ldots]$ da lui tanto perfettamente appresa da Gio. Bellini $[\ldots]$ ma ora molto consumate, e quasi rese invisibili dalla Pioggia e dal Tempo." Per il testo di Milesio relativo alle due altre facciate si veda più sotto il testo e la nota 108 .

${ }^{81}$ Come è noto,Vasari (o chi per lui) vide o credette di vedere una figura affiancata da una testa di leone (Ercole?) e un angelo "a guisa di Cupido" (un genio alato?):Vasari, 2001, p. 118.

82 Il Vasari descrisse minuziosamente la facciata del palazzo di Sforza Almeni proprio perché solo quattordici anni dopo la sua esecuzione era già guasta dal maltempo: "Né voglio che mi paia fatica raccontare gli spartimenti e figure di quest'opera, la quale potrebbe non aver lunghissima vita, per esser all'aria e molto sottoposta ai tempi fortunosi; né era a fatica fornita, che da una terribile pioggia e grossissima grandine fu molto offesa, ed in alcuni luoghi scalcinato il muro" (Vasari (1568), 1906, pp. 232-233).

${ }^{83}$ Vasari (1568), 2001, p. 118: "V'è bene sopra la porta principale che riesce in Merzerì una femina a sedere, c'ha sotto una testa d'un gigante morta, quasi in forma d'una Iuditta, ch'alza la testa con la spada e parla con un todesco, quale è abasso: né ho potuto interpretare per quel che se l'abbi fatta, se già non l'avesse voluta fare per una Germania." Come è noto,Vasari descrisse la Giuditta una prima volta nella vita di Giorgione per poi attribuirla a Tiziano nella biografia a lui dedicata. Perché ciò accadesse è spiegato per la prima volta in modo plausibile da Charles Hope in questo volume.

${ }^{84}$ In un tondo alle spalle della figura si leggono le lettere "R.A." che Valcanover scioglie in Regum Ars: F.Valcanover, Frescoes from the Fondaco dei Tedeschi, in: Titian. Prince of Painters, Venezia 1990, pp. 136-138.

${ }^{85}$ M. Muraro, ,,The Political Interpretation of Giorgione's Frescoes on the Fondaco dei Tedeschi”, in: Gazette des BeauxArts 117 (1975), vol. LXXXVI, pp. 177-184.

${ }^{86}$ G.B. Cavalcaselle e J.A. Crowe, Tiziano, la sua vita e $i$ suoi tempi, Firenze 1877-78, ristampa anastatica, Firenze 1974, 2 voll.

${ }^{87}$ Muraro, 1975, p. 180.

${ }^{88}$ Simonsfeld, 1887, vol. 1, p. 353, n. 641.

${ }^{89}$ Muraro, 1975, p. 177.

${ }^{90}$ Muraro, 1975, p. 181.

91 Concina, 1997, p. 153.

92 K.-E. Lupprian, Il Fondaco dei Tedeschi e la sua funzione di controllo del commercio tedesco a Venezia, Venezia 1978, p. 9. 
93 D. Chambers e B. Pullan, a cura di, Venice. A Documentary History 1450-1630, Oxford 1992, p. 330, nota 3.

94 Muraro, 1975, p. 181.

95 Maschio, 1994, p. 198, nota 61.

96 Ch. Hope, Titian's Life and Times, in: a cura di D. Jaffe, Titian, Londra 2003, p. 186, nota 4, ritiene illogico datare gli affreschi di Tiziano al 1509 poiché le impalcature avrebbero ostacolato l'ingresso degli affittuari delle botteghe i cui proventi stavano a cuore agli amministratori dello Stato, ma gli spazi sotto le finestre al centro della facciata potevano essere realizzati da ponteggi relativamente bassi e poco ingombranti. Se la data autunno 1508 è quindi preferibile, è possibile che l'artista affrescasse il gruppo della Giuditta, senza creare eccessivi disagi, anche nella primavera del 1509.

97 Ch. Hope, Titian, Londra 1980, pp. 12-13 contesta la tradizionale identificazione di questa figura con la Giustizia e sottolinea come nel Rinascimento Giuditta non fosse considerata una personificazione della Giustizia bensì della Fortezza.

98 E. Wind, Giorgione's Tempesta with Comments on Giorgione's Poetic Allegories, Oxford 1969, p. 13.

${ }^{99}$ L'idea, errata, che Tiziano operasse al Fondaco in qualità di assistente di Giorgione risale al Cavalcaselle: Cavalcaselle e Crowe (1877-78), 1974, vol. 1, p. 71.

${ }^{100}$ Wind, 1969 , fig. 42.

101 Ch.E. Cohen, "Pordenone, not Giorgione", in: The Burlington Magazine 122 (1980), pp. 601-607.

102 Sul tema della pace e della giustizia si veda anche Concina, 1997, pp. 190-196.

103 L'ipotesi e le sue contraddizioni sono discusse in ogni dettaglio da P. Joannides, Titian to 1518. The Assumption of Genius, New Haven e Londra 2001, pp. 65-67. Joannides identifica le due figure incise dallo Zanetti con la Speranza e la Carità, ma se Tiziano avesse voluto rappresentare le virtù teologali mancherebbe la Fede all'appello.

104 Antonio Averlino, detto il Filarete, Trattato di architettura, a cura di A.M. Finoli e L. Grassi, Milano 1972, pp. 275-276.

105 In queste vedute il Fondaco svetta sul quartiere circostante in modo sproporzionato e poco attendibile da un punto di vista documentario: si vedano i dettagli delle piante di Giovanni Andrea Vavassore (circa 1535) e di Matteo Pagan (1559) in J. Schulz, "The printed plans and panoramic views ofVenice (1486-1797)", in: Saggi e memorie di storia dell'arte 7 (1970), p. 124 fig. 14 e p. 130 fig. 20. Che l'ingresso princi- pale al Fondaco fosse praticamente bloccato da due casupole, come evidenzia la veduta di Venezia di Paolo Forlani del 1566, è del tutto da escludere, confermando quanto sia imprudente basarsi su tali fonti: per l'immagine si veda fig. 17.

$106 \mathrm{Su}$ questo punto si veda soprattutto S. Romano, Giuditta $e$ il Fondaco dei Tedeschi, in: Giorgione e la cultura veneta tra' 400 e '500. Mito, Allegoria, Analisi iconologica (Atti del Convegno, Roma, Novembre 1978), Roma 1981, pp. 113-125.

107 Cicognara, Diedo e Selva, 1858, p. 151 e tavola 93.

108 Milesio (circa 1715), in Thomas, 1881, p. 43. La quarta facciata era decorata nel modo seguente: "Quarta Facciata a Tramontana sopra il rio del Fontico. In questa Facciata non si scorge quasi più némeno il colorito non che le figure e particolarmente in alto. Dal mezo in giù vedesi qualche fregio, ma il Bello fatto dalla virtù del suddetto Giorgione è stato divorato dalla Tramontana” (id., p. 43).

${ }^{109}$ Holberton, 1989, pp. 46-52.

${ }^{110}$ M. Boschini, Le ricche Minere della Pittura veneziana, Venezia 1674, p. 109.

111 Per le illustrazioni si veda Joannides, 2001, p. 65, figure 49 e 50.

112 Per il problema creato da una postilla in mano cinquecentesca aggiunta in margine al Diario di Marcantonio Michiel, spesso menzionata nella letteratura sul Fondaco, un'annotazione che identifica uno degli effigiati con l'uomo d'arme Zuan Favro, ricordato dal Sanudo per un fattaccio di contrabbando avvenuto dopo l'esecuzione degli affreschi, Charles Hope mi segnala gentilmente che essa risale al 1571 e non dovrebbe quindi essere presa in considerazione nella già complicata questione degli affreschi di Tiziano. Il testo della postilla recita: "Questo Zuan Favro è depento sopra il fontego di todeschi sopra il cantonal grande verso San Bartolomio. Era valentissimo homo della sua vita."

${ }^{113}$ Ridolfi (1648), 1914, vol. 1, pp. 154-155.

${ }^{114}$ J. Schulz, ,,Titian at the Fondaco dei Tedeschi”, in: The Burlington Magazine 143 (2001), pp. 567-569.

$115 \mathrm{Si}$ veda a questo proposito la pianta incisa da Vincenzo Fadiga e pubblicata dall'équipe del Cicognara in Le fabbriche e i monumenti cospicui di Venezia, Venezia 1858, tavola 93: sul lato sud si aprivano dieci botteghe, sul lato est ve n'erano nove; non si capisce se all'angolo ci fosse un negozio più grande oppure se le botteghe fossero undici sulla calle delle Mercerie e dieci sulla salizzada. 